\title{
IMPACT OF MUTATION DENSITY AND HETEROGENEITY ON PAPILLARY THYROID CANCER CLINICAL FEATURES AND REMISSION \\ PROBABILITY
}

\author{
Carla Colombo ${ }^{1,2 *}$, Marina Muzza ${ }^{1,2,3 *}$, Maria Carla Proverbio ${ }^{2}$, Delfina Tosi $^{4,5}$, Davide
} Soranna ${ }^{6,7}$, Chiara Pesenti ${ }^{2,8}$, Stefania Rossi ${ }^{4}$, Valentina Cirello ${ }^{1}$, Simone De Leo ${ }^{1,2}$, Nicola Fusco $^{8,10}$, Monica Miozzo ${ }^{2,8}$, Gaetano Bulfamante ${ }^{4,5}$, Leonardo Vicentini ${ }^{9}$, Stefano Ferrero $^{8,10}$, Antonella Zambon ${ }^{6,7}$, Silvia Tabano ${ }^{2,8}$, Laura Fugazzola ${ }^{1,2}$

${ }^{1}$ Division of Endocrine and Metabolic Diseases, IRCCS Istituto Auxologico Italiano, Milan; ${ }^{2}$ Department of Pathophysiology and Transplantation, Università degli Studi di Milano, Milan; ${ }^{3}$ Endocrine Unit, Fondazione IRCCS Ca' Granda-Ospedale Maggiore Policlinico, Milan; ${ }^{4}$ Unit of Pathology, ASST Santi Paolo e Carlo, Milan; ${ }^{5}$ Department of Health Sciences, Università degli Studi di Milano, Milan; ${ }^{6}$ Department of Statistics and Quantitative Methods, University of Milano-Bicocca, Milan; ${ }^{7}$ IRCCS Istituto Auxologico Italiano, Milan; ${ }^{8}$ Division of Pathology, Fondazione IRCCS Ca' Granda Ospedale Maggiore Policlinico, Milan; ${ }^{9}$ Endocrine Surgery Unit, IRCCS Istituto Auxologico Italiano, Milan; ${ }^{10}$ Department of Biomedical, Surgical and Dental Sciences, Università degli Studi di Milano, Milan, Italy

*Equal contributors

Running head: Mutation density in papillary thyroid cancer

Key words: Papillary Thyroid Carcinoma, MassARRAY, NTRK1, BRAF, TERT, heterogeneity

\section{Corresponding author:}

Laura Fugazzola

Division of Endocrine and Metabolic Diseases, IRCCS Istituto Auxologico Italiano Department of Pathophysiology and Transplantation, Università degli Studi di Milano, P.le Brescia 20, 20149, Milano, Italy laura.fugazzola@unimi.it 


\section{ABSTRACT}

Background: The need to integrate the classification of cancer with information on the genetic pattern has emerged in recent years for several tumors.

Patients and methods: The genomic background of a large series of 208 papillary thyroid cancers (PTC) followed at a single Center was analyzed by a custom MassARRAY genotyping platform (PTC-MA), which allows the simultaneous detection of 19 common genetic alterations including point mutations and fusions.

Results: $71 \%$ of the PTCs were found to have pathognomonic genetic findings, with $B R A F^{\mathrm{V} 600 \mathrm{E}}$ and TERT promoter mutations being the most frequent monoallelic alterations (42 and $23.5 \%$, respectively), followed by RET/PTC fusions. In $19.2 \%$ of cases, two or more point mutations were found, and the co-occurrence of a fusion with $\geq 1$ point mutation/s was also observed. Coexisting $B R A F^{\mathrm{V} 600 \mathrm{E}}$ and TERT promoter mutations were detected in a subgroup of aggressive PTCs (12\%). A correlation between several aggressive features and mutation density was found, regardless of the type of association (i.e. only point mutations, or point mutations and fusions). Importantly, Kaplan Meier curves demonstrated that mutation density significantly correlated with a higher risk of persistent disease. In most cases, the evaluation of the allelic frequencies normalized for the cancer cell content indicated the presence of the monoallelic mutation in virtually all tumor cells. A minority of cases was found to harbor low allelic frequencies, consistent with the presence of the mutations in a small subset of cancer cells, thus indicating tumor heterogeneity. Consistently, the presence of coexisting genetic alterations with different allelic frequencies in some tumors suggests that PTC can be formed by clones/subclones with different mutational profiles.

Conclusions: A large mono-institutional series of PTCs was fully genotyped by means of a cost- and time-effective customized panel, revealing a strong impact of mutation density and genetic heterogeneity on the clinical features and on disease outcomes, indicating that an accurate risk stratification of thyroid cancer cannot rely on the analysis of a single genetic event. Finally, the heterogeneity found in some tumors warrants attention, since the occurrence of this phenomenon is likely to affect response to targeted therapies. 


\section{INTRODUCTION}

Well-differentiated papillary thyroid cancer (PTC) is the most common type of thyroid malignancy, representing up to $80 \%$ of the cases. In the last decades, a relevant rise in PTC incidence has been documented worldwide (1). Although PTC has in general a good prognosis, a small fraction shows higher aggressiveness and therapeutic options are limited for patients not cured by surgery and radioiodine (2).

Monoallelic somatic genetic events in the MAP kinase pathway are found in about $80 \%$ of PTCs, including point mutations of BRAF and RAS genes, and RET-PTC and TRK rearrangements (3). $B R A F^{\mathrm{V} 600 \mathrm{E}}$ mutation is the most frequent genetic change, with $a$ prevalence of $23-83 \%$ among different series and it is found in both the classic and more aggressive variants of PTC. There are still controversial data on the relationship between the $B R A F^{\mathrm{V} 600 \mathrm{E}}$ mutation and a worse outcomes, and its role as a prognostic factor in PTC is controversial (4-6).

More recently, two mutations in the promoter of the telomerase reverse transcriptase (TERT) gene, c.-124 C>T (C228T) and c.-146 C>T (C250T), have been reported in PTC, with a prevalence ranging from 5 to 15\% (2). TERT is the catalytic subunit of telomerase, which maintains telomeres at the end of chromosomes, and its reactivation has been implicated in human tumorigenesis. In PTC, an association between TERT $T^{\mathrm{C228T}}$ and TERT $T^{\mathrm{C250T}}$ mutations and older age at diagnosis, tumor size, distant metastases, reduced progression free survival and overall survival has been shown (7-9), indicating a prognostic value of these genetic alterations in the risk stratification of patients. TERT mutations have been reported to be frequently associated with BRAF mutations in PTC, and this duet is associated with aggressive clinico-pathological features $(10,11)$.

Recently, an integrated genomic characterization of a large series of 402 PTCs from several USA Referral Centers, The Cancer Genome Atlas (TCGA), extended the set of known PTC driver alterations, including point mutations in the EIF1AX gene and BRAF gene fusions, reducing the fraction of PTC cases with unknown oncogenic drivers (12). Somatic mutations were found in $83 \%$ and gene fusions in $13 \%$ of them, mostly affecting the RAS/RAF/MAPK pathway, with BRAF (61.7\%), RAS (12.9\%), TERT (9.4\%) and RET/PTC (6.8\%) as the most frequent genetic events. Another interesting finding of this study is that 
mutation density appeared to be highly correlated with aggressive histologic features and risk of recurrence.

A recent study from China reported the analysis of 138 PTC samples using the NGS cancer panel ThyGenCapTM (13). The most frequent genetic event was $B R A F^{\mathrm{V} 600 \mathrm{E}}(58 \%)$, followed by RET fusions (5\%), whereas all the other genetic alterations were well below $5 \%$, including KRAS and HRAS (2.2 and 0.7\%, respectively), TERT mutations (1.4\%), and TRK rearrangements (2.1\%). A strong association with distinct clinico-pathological characteristics was identified.

In this study we did not aim to fully genotype our large monoinstitutional series of PTCs, or to discover possible novel genetic events, but to characterize them for the 19 most frequent genetic alterations. Genetic data, including the evaluation of the allelic frequencies of the driver oncogenes, were obtained by a customized, reliable, highly timeand cost-effective Mass Array genotyping platform (PTC-MA), recently developed by our group (14), and were then compared with several clinical features and with the disease outcome.

\section{PATIENTS AND METHODS}

\section{Patients and clinical data}

This is a retrospective cohort study with institutional review board approval (\#2018_09_25_04) and informed patient consent for the use of thyroid tumor tissues and collection of clinico-pathological information. A large series of 208 patients with PTC (157 F, $51 \mathrm{M}, 95 \%$ of Caucasian origin), all operated and followed over a period of 21 years at the same Referral Center, was included in this study. The clinical features are listed in Supplemental Table 1. All specimens were reviewed by three senior pathologists (S.F., G.B. and S.R.) to confirm the diagnosis. Tumors have been classified/re-classified and staged/restaged according to the $8^{\text {th }}$ edition of the TNM staging system (15). The following histologic types were present: classical, follicular, sclerosing, columnar and poorly differentiated variants (Figure 1). All patients, are included in a comprehensive database which contains clinical and pathologic information. Criteria used to identify remission or persistent/recurrent disease (outcome) were based on the bases of the American Thyroid Association guidelines for the management of differentiated thyroid cancer (16). 


\section{DNA and RNA Extraction, and Reverse Transcription}

Genomic DNA and RNA were extracted from the 208 PTCs (104 fresh frozen tissues and 104 formalin fixed paraffin embedded-FFPE-tissues). For frozen samples, tumors $<1.5 \mathrm{~cm}$ were microdissected to ensure high tumor tissue content; in larger tumors, the core of the sample was macroscopically dissected. For FFPE samples, hematoxylin \& eosin sections were evaluated to define tumor purity which corresponds to the amount of sample occupied by cancer cells and not by surrounding stromal and immune/inflammatory cells, that is, the percentage of neoplastic cells. In order to mitigate variability, the quantification of neoplastic cells was performed by two experienced pathologists (G.B. and S.R.) always in the same section used for sequencing. A minimum of $10 \%$ tumor purity was required for sample processing. Genomic DNA was extracted using a commercial kit from either frozen or FFPE tissues (Puregene ${ }^{\circledR}$ Core Kit A, Qiagen, Germantown, MD, USA), following the manufacturer's instructions. Total RNA was extracted from frozen or FFPE tissue samples using a Trizol-based commercial kit (Thermo Fisher, Waltham, MA, USA), according to the manufacturer's protocol. One $\mu \mathrm{g}$ of each RNA sample was reverse transcribed using a Superscript reverse transcriptase II Kit (Thermo Fisher), with a hexamer mixture as primers. ACTB amplification from the CDNA was performed as an internal quality control.

\section{PTC-MA Assay for Identification of Hotspot Somatic Mutations and Fusion Genes}

The custom PTC-MA assay, based on MALDI-TOF Mass spectrometry, has been previously set up by our group and allows the simultaneous detection of 13 hotspot mutations and 6 recurrent fusion genes typical of PTC, in a sensitive, fast, and economic way (14). This assay is able to detect the presence of point mutations and fusion genes with a sensitivity of $5 \%(14)$.

In brief, three multiplex PCR reactions were used: Mix 1 was performed using genomic DNA, with intronic/exonic PCR primers for the identification of point mutations. Mix 2 and 3 were used to assess CDNA, with exonic PCR primers for the identification of both point mutations located within exons and fusion genes. The complete list of genetic alterations screened using the PTC-MA panel is reported in Figure 1. In detail, the following point mutations were analyzed in the PTC-MA assay: BRAF V600E, AKT1 E17K, EIF1AX c.3381G>C, NRAS Q61R and NRAS Q61K, HRAS G13C, HRAS Q61K and HRAS Q61R, KRAS G12V and KRAS G13C, TERT c.-124C>T and TERT c.-146C >T, and PIK3CA E542K. The following 
fusion genes were assessed: RET/PTC1 (RET/CCDC6), RET/PTC2 (RET/PRKAR1A), and RET/PTC3 (RET/NCOA4) for the RET gene, and TRK (NTRK1/TPM3), TRK-T1 (NTRK-T1/TPR), and TRK-T3 (NTRK1/TFG) for the NTRK1 gene. Since TERT and EIF1AX mutations and AKT1 PCR primers are located in non-coding sequences, they were analyzed using genomic DNA template. The remaining mutations are all located within exons and were analyzed using exonic PCR primers, starting from either genomic DNA or cDNA. The choice of the biological starting material was made to optimize the multiplex PCRs by minimizing the interference among the extension primers. cDNA was also used to analyze the six fusion genes, by means of PCR primers designed so that each hybridized to one of the two partner genes involved in the rearrangement. PCR products were obtained only in the presence of the rearrangement, whereas in wild-type samples, no amplification was possible. gDNA and cDNA (approximately $30 \mathrm{ng}$ ) were used for PCR, SAP (shrimp alkaline phosphatase), and Single Base Extension (SBE) reactions, which were conducted using the Complete iPLEX Pro Genotyping Reagent Set (Agena Bioscience, San Diego, CA, USA), following the manufacturer's protocol. SBE products were processed on SpectroCHIP II Arrays using a Clean Resin Kit and the MassARRAY Nanodispenser (Agena Bioscience), and then analyzed using MassARRAY Typer 4.0 software (Agena Bioscience).

For point mutations, but not for fusions, the allelic frequencies were recorded and normalized for the cancer cell content, in order to estimate the frequency of mutant alleles in cancer cells. For fusion genes, the allelic frequency cannot be evaluated since their detection involves a selective amplification of the rearranged gene transcript. The percentage of cancer/normal cells was calculated based on the section adjacent to the sample used for nucleic acids extraction. In particular, the percentage of tumor cells was calculated in each sample by looking at 100 cells in 4 fields at a magnification of $40 \mathrm{X}$. For each field, the number of cancer cells among 100 cells were counted and a mean of the results obtained in the 4 fields was calculated. Major contaminants were normal thyrocytes, lymphocytes, stromal cells and endothelial cells.

\section{PCR and Sanger Sequencing}

In $128 / 208$ cases (61.5\%), the genetic analysis of BRAF, TERT, RAS and RET/PTC had been ca rried out in previous years by amplification and direct sequencing ( $A B \mid 3130$, Thermo Fisher ) , as already reported $(8,17,18)$. 


\section{Statistics}

To analyze the association between genetic variants and clinical parameters, we summarize

$\mathrm{d}$ continuous data using means \pm SD (or median and range interquartile) and categorical da ta using frequencies and percentages. T-test (or Wilcoxon rank sum test in case of no norm ality) was used to test the difference of the mean of the continuous variables between pati ents with and without a mutation of a specific gene. The Chi-square test (or Fisher test) wa $s$ used when appropriate to test the differences of the categorical variables. A linear model was applied to verify the association between allele frequency and tumor size. 10 year surv ival curves by mutation density (dichotomized as $\leq 1$ or $\geq 2$ mutations) were examined by Ka plan-Meier analyses with log-rank test, censoring patients at the time of patient remission or, in the case of no remission, at the time of last clinical contact. A proportional hazard reg ression Cox model was applied to estimate the association between mutation density and probability of remission adjusted for the most important confounders: age, sex, and tumor size. The association was expressed as Hazard Ratio (HR) and relative $95 \%$ confidence inter val $(95 \% \mathrm{Cl})$. Statistical significance was defined as $\mathrm{P}<0.05$ or $\mathrm{P}<0.10$. All statistical analyses were performed using SAS version 9.2.

\section{RESULTS}

\section{Genotyping}

At least one genetic variation, either a point mutation or fusion, was found in $148 / 208$ cases $(71 \%)$, always in heterozygosity. As shown in Figure 2, the $B R A F^{\mathrm{V} 600 \mathrm{E}}$ variant was the most frequently found mutation (87/208 cases, 42\%). The frequency of TERT promoter mutations was high $(49 / 208,23.5 \%)$; the majority consisted of the c.-124 (46/49, 94\%) mutation while c.-146 (3 cases, 6\%) was less prevalent. RAS point mutations were documented in 13/208 cases (6.2\%; $\mathrm{n}=7$ NRAS Q61R, $\mathrm{n}=2$ NRAS Q61K; $\mathrm{n}=2$ HRAS Q61R, $\mathrm{n}=1$ HRAS Q6K; $\mathrm{n}=1$ KRAS G13C). RET fusions were found in 37/208 cases (18\%), with a predominance of RET/PTC1 $(\mathrm{n}=26)$ compared to RET/PTC3 rearrangements $(\mathrm{n}=11)$. TRK fusions were documented in 5/208 tumors (2.4\%): a TRK fusion was found in 1, and TRKT1 fusions in 4 cases. No mutations were found in the AKT1, EIF1AX and PIK3CA genes nor were there any RET/PTC2 rearrangements, confirming that they are rarely involved in the pathogenesis of PTC. 
In $40 / 208$ cases (19.2\%) two or more mutations were found In particular, the cooccurrence of TERT with BRAF was detected in $25 / 208$ cases (12\%), and with RAS in 1/208 cases (0.5\%). Among BRAF mutated cases $(n=87)$ and RAS mutated cases $(n=14)$, the frequencies of an association with TERT mutations were of 28.7 and $7.1 \%$, respectively. The co-occurrence of a fusion with $\geq 1$ point mutation/s was found in 13/208 (6.3\%) of cases (10 RET/PTC1, namely with BRAF $(\mathrm{n}=4)$, with TERT $(\mathrm{n}=3)$, with RAS $(\mathrm{n}=1)$, with BRAF and TERT $(\mathrm{n}=1)$, and with RAS and TERT $(\mathrm{n}=1) ; 2 \operatorname{RET} / P T C 3$, namely with TERT $(\mathrm{n}=1)$ and with BRAF and TERT $(\mathrm{n}=1) ;$ TRK-T1 with BRAF $(\mathrm{n}=1))$. In two cases, 2 different gene fusions were found in the same tumor (1 TRK-T1 and RET/PTC3 and 1 TRK-T1 and RET/PTC1). Finally, the co-occurrence of 2 fusions (TRK-T1 and RET/PTC) and the TERT mutation was found in 1 case who, at 28 years of age was treated with total thyroidectomy and a total of $15,921 \mathrm{MBq}$ of $131 \mathrm{l}$ for a $4.5 \mathrm{~cm}$ classic PTC with lymph node metastases. At the last follow-up visit, there was evidence of residual disease and the tumor was found be refractory to radioiodine. Interestingly, this patient had been submitted to chemotherapy during childhood for an acute lymphoblastic leukemia which is now in complete remission.

\section{Sensitivity of PTC-MA with respect to Sanger sequencing}

About $60 \%$ of the cases analyzed by PTC-MA assay had been previously analyzed by Sanger sequencing. Sequencing and mass spectrometry were $100 \%$ concordant for fusions, whereas BRAF, TERT and RAS mutations were missed by Sanger sequencing in 3.8 (2/53), $30(9 / 30)$ and $11.1 \%(1 / 9)$ of the samples respectively, indicating the higher sensitivity of the PTC-MA assay in tumor genotyping, especially for tumors harboring allelic frequencies $<20 \%$ (Supplemental Figure 1).

\section{Allelic frequencies}

A major benefit of the MA technology is that it provides automatically, for point mutations, the percentages of the wild-type and mutated alleles detected at each investigated locus, thus indicating the level of heterogeneity of the tumor tested and the percentage of cells that underwent a given genetic event. The high variability in allelic frequencies found among different tumors could be consistent with the variable number of tumor cells obtained from each specimen. Indeed, in several tumors, a wild-type allele contamination is usually found due to the presence of stromal, endothelial, and inflammatory cells (Figure $\mathbf{3 A}$ ). The contamination is predicted to be higher in smaller 
tumors, as it is more difficult to selectively dissect the tumor mass. Accordingly, we found a positive correlation between the tumor size and the allele frequency of the mutation obtained by the PTC-MA assay $(P=0.0001)$. This finding highlights the need to normalize for the cancer cell content of the sample in order to obtain an estimate of the allelic frequency of the mutation (Supplemental Table 2). Consistently, the correlation between tumor size and allelic frequency was lost when the allelic frequencies were normalized for the cancer cell content ( $P=0.29$, Figure 3B). Assuming that somatic mutations usually affect one allele, the frequency of mutant cells in neoplastic samples can be obtained by multiplying by 2 the normalized allelic frequencies (i.e. an allelic frequency of $50 \%$ suggests that all neoplastic cells carry the mutation). In this series, the means \pm SD normalized allelic frequencies were $49.91 \pm 11.22$ (mode: 51 , range $22-100$ ) for $B R A F, 53.26 \pm 18.65$ (mode 58, range 3-111) for TERT, and $48.61 \pm 8.13$ (mode 47, range 25-57) for RAS mutations. Thus, in the majority of the tumor tested, the normalized allelic frequencies were consistent with the presence of the heterozygous mutation in virtually all the neoplastic cells. On the other hand, a minority of cases was found to harbor low allelic frequencies, indicating that the mutations are present in a small subset of cancer cells, thus reflecting tumor heterogeneity. Another subset of less than 10 cases showed an allelic frequency higher than $50 \%$, possibly indicating a clonal event plus deletion of the wild type allele (19). Interestingly, in some cases with multiple mutations, the frequency of the mutant alleles was different among the affected genes, thus indicating intratumoral heterogeneity. No significant correlation was found between allelic frequencies and age, stage of the tumor or outcome (data not shown). Finally, as an additional test to verify the reliability of our assay in the identification of the allelic frequency, we calculated the allelic frequencies of BRAF and TERT mutations in the BCPAP cell line, which is known to harbor these variants in homozygosity, and we found that $100 \%$ of the alleles had both mutations, whereas in the NIM cell line, known to harbor $B R A F^{\mathrm{V} 600 \mathrm{E}}$ in heterozygosity (20), we found 50\% mutated alleles (Supplemental Figure 2).

\section{Correlation with clinical and pathological features}

We compared several clinical features among PTCs that did not display any of the genetic alterations analyzed in this study and PTCs with $\geq 1$ genetic alteration/s. BRAF V600E mutations, which showed an increased frequency over a 21 year period (1995-2016), were 
more frequent in cases with more aggressive clinical features such as tumor size, extrathyroidal invasion, and higher AJCC stage and ATA risk category. TERT mutations were associated with older age at diagnosis and with a higher AJCC stage, whereas RAS mutations were associated with the follicular variant and a lower ATA risk (Table 1A). Interestingly, cases harboring the genetic duet of BRAF and TERT mutations showed several features of higher aggressiveness, such as larger tumor size, extrathyroidal invasion, and AJCC stage and ATA risk compared to cases wild-type for these alterations or with a single mutation (Table 1B). No significant correlations were found between clinical parameters and fusions, but regarding TRK rearrangements this was likely just the consequence of the low number of mutated cases. Indeed, all TRK mutated cases had a tumor size $\geq 2 \mathrm{~cm}$, with lymph node metastasis, and an intermediate/high risk at ATA classification (Table 1C).

An original result of this study is the evaluation of the impact of mutation density on disease outcome. The evaluation of the clinico-pathological features according to the number of genetic events, i.e. $\leq 1$ or $\geq 2$, showed a significant correlation between the number of mutations and more aggressive features, such as tumor size, extrathyroidal invasion, and AJCC stage (Table 2). Kaplan Meier curves demonstrated that the presence of $\geq 2$ genetic events was associated with a significantly higher risk to have persistent disease at the last follow-up (Log Rank test=0.037) (Figure 4). There was a much higher probability of remission in patients harboring none or 1 mutation compared to patients harboring $\geq 2$ mutations (HR 1.505 (95\% Cl $0.936-2.420)$ P-value=0.092). This significance was lost after additional adjustment for aggressive tumor features, which were significant at univariate analysis, such as extrathyroidal invasion and AJCC stage.

\section{DISCUSSION}

Recent advances in the molecular classification of thyroid cancer has improved the diagnostic work-up and the care of patients with thyroid nodules and cancer $(12,21,22)$, highlighting the need to routinely add information on the genetic pattern. In this study, the genomic background of a large series of PTCs followed at a single center has been defined by the PTC-MA assay, and around $20 \%$ of the mutated tumors were found to harbor two or more different genetic events, always in liited to one allele. A correlation between several 
aggressive features (size, extrathyroidal extension, AJCC stage) and mutation density was found, regardless of the type of mutations (i.e. only point mutations, or point mutations and fusions). Kaplan Meier curves demonstrate that the presence of $\geq 2$ genetic events was associated with a significantly higher risk to have persistent disease at the last follow-up. Likely due to the limited number of samples with multiple mutations, the significance was lost after multivariable adjustments for known risk factors. This finding indicates that an accurate risk stratification of thyroid cancer cannot rely on the analysis of a single genetic event. The biological bases underlying the coexistence of different genetic events in thyroid cancer is still debated and the scanty data available indicate that they could be present in the same cell or in different cells (23-27), consistent with the presence of intratumor heterogeneity (27). The actual occurrence of this phenomenon in PTC is supported by the analysis of the allelic frequencies for BRAF, TERT and RAS mutations. The presence of coexisting genetic alterations with different allelic frequencies in some tumors suggests that PTC can be formed by clones/subclones with different mutational profiles, in agreement with previous data and with studies in other tumors (28-30). Interestingly, we found that PTCs of larger size have a significantly greater proportion of mutated alleles, either BRAF, TERT or RAS within the tumor, similar to data previously reported $(28,29)$. This result is very likely due to the better isolation of the tumor mass from the surrounding parenchyma in larger tumors, with a higher contamination of noncancer cells in smaller specimens. Consistently, the correlation between tumor size and allelic frequency was lost when the latter was normalized for the cancer cell content. In the majority of the cases tested, the evaluation of the allelic frequencies normalized for the cancer cell content indicated the presence of the heterozygous mutation in virtually all tumor cells, in agreement with NGS and immunohistochemical data (12, 26, 29, 31). Clinico-pathological features were not associated with the allelic frequencies of driver oncogenes, indicating that at present allelic frequencies cannot be used to optimize the prognostic prediction. On the other hand, the finding that some tumors are heterogeneous with respect to a specific mutation might have important implications for therapeutic approaches. We expect that tumors that carry a specific molecular alteration only in a fraction of neoplastic cells might show a low level of sensitivity to targeted agents. 
However, the complexity revealed by our study suggests that, for many tumors, combinations of targeted drugs will likely be necessary to control tumor growth.

$B R A F^{\mathrm{V} 600 \mathrm{E}}$ was the most frequently found genetic event ( $42 \%$ of cases), and the frequency of TERT promoter mutations was higher (23.5\%) than previously reported in our own and other series $(7,8,9,12)$. The most plausible explanation for this result resides in the higher sensitivity of our PTC-MA assay compared to the standard methods used in some published series $(7,8,9)$. Indeed, the PTC-MA assay is able to detect sequence alterations present in only $5 \%$ of cells which were uncertain or missed by Sanger sequencing (14). Interestingly, sequencing and mass spectrometry were $100 \%$ concordant for fusions, whereas among single nucleotide variants, TERT mutations were the most frequently event missed by Sanger sequencing, when present at low allelic frequency. The very high GC content of the TERT sequence could explain the lower sensitivity of Sanger or other PCR-based technologies. Another explanation could reside in the fact that TERT mutations occur later in tumor progression, when a high number of stromal cells are present in the tumor mass (32). Finally, the differences with series analyzed by high throughput methods (12) could be related to the clinical characteristics of the samples analyzed or by epidemiologic reasons, as suggested by the highly discrepant frequencies of TERT mutations in series from the United States and China ( $10 \%$ and $<3 \%$, respectively) $(12,13)$. Moreover, consistent with previous data (33), the analysis of the mutational distribution over the last years 21 years revealed that the genetic profile of PTC is changing, with an increased frequency of BRAF and TERT mutations, particularly in the last 5 years, a period that was not included in the TCGA analysis (12).

It is worth to note that almost half of the TERT mutations were associated with BRAF variations or with RET fusions, confirming that they frequently occur as a second mutational event. Nevertheless, TERT was the only mutated gene in several cases, indicating that it carries its own tumorigenic potential. A strong cooperative role of coexisting $B R A F^{\mathrm{V} 600 \mathrm{E}}$ and TERT promoter mutations in the development of a group of PTCS displaying the highest clinico-pathological aggressiveness has been found, confirming the central prognostic value of the association $(8,10,34)$.

RAS point mutations had a prevalence of $6.2 \%$, and were mostly due to a NRAS involvement, and it was tightly associated with the follicular PTC variant, consistent with 
findings of the TCGA (12). Interestingly, TRK rearrangements, though rare (2.4\%), were found only in young patients and were associated with aggressive features, as previously highlighted in a pediatric population (35). Of note, there are only limited data on tumors harboring this genetic event since the majority of molecular diagnostic tests currently used for thyroid tumors do not cover TRK gene fusions. Nevertheless, our results highlight that these fusions must be routinely analyzed, also in view of the recent availability of a smallmolecule, highly selective tyrosine receptor kinase inhibitor, which offers new possibilities for the treatment of these patients.

The main limitation of the PTC-MA approach, is that only targeted point mutations and stable breakpoints can be analyzed. For that reason, the present genetic analysis did not include some of the mutations recognized to be pathogenic for thyroid cancer (e.g. MET, $A L K, B R A F$ fusions, p53). Nevertheless, those mutations are rare in PTCs, being reported with a prevalence range $0.2-2.3 \%$ in the TCGA (12). Moreover, it is noteworthy that cases with none of the genetic events tested by the PTC-MA assay have typically no aggressive features and a good outcome, indicating that they are likely caused by mutations with a low transforming power. Thus, we believe that the coverage offered by our customized panel could be of significant importance in the definition of the genetic pattern of most PTC cases and, in particular, of those with a more aggressive behavior, even though it will be continuously improved to cover other genetic alterations. Our approach has a major translational relevance since, in the era of personalized medicine, it raises the need to set up cost- and time-effective techniques to investigate multiple molecular markers, especially those with a known prognostic impact or that can be targeted pharmaceutically. Finally, the relatively high level of heterogeneity found in the genotyped tumors warrants attention, since the occurrence of this phenomenon is likely to affect response to targeted drugs. The assessment of such complexity, for instance by the analysis of paired primary and metastatic samples from the same patient to acquire insights into clonality and subclonality patterns of genomic events, is mandatory for the further development of personalized medicine in thyroid cancer. 


\section{Declaration of interest}

The Authors declare that there is no conflict of interest that could be perceived as

prejudicing the impartiality of the research reported

\section{Funding}

This research did not receive any specific grant from any funding agency in the public, commercial or not-for-profit sector

\section{Author contributions}

Conception and design: Laura Fugazzola

Financial support: Laura Fugazzola

Administrative support: Laura Fugazzola

Provision of study materials or patients: Carla Colombo, Simone De Leo, Stefania Rossi, Gaetano Bulfamante, Nicola Fusco, Stefano Ferrero, Laura Fugazzola

Collection and assembly of data: Carla Colombo, Marina Muzza, Delfina Tosi, Maria Carla Proverbio, Chiara Pesenti, Valentina Cirello, Monica Miozzo, Silvia Tabano, Laura Fugazzola

Data analysis and interpretation: Carla Colombo, Marina Muzza, Laura Fugazzola

Statistics: Davide Soranna, Antonella Zambon

Manuscript writing: All authors

Final approval of manuscript: All authors

Accountable for all aspects of the work: All authors

\section{ACKNOWLEDGEMENTS}

The Authors wish to acknowledge the invaluable contribution of Dr. Emanuela Minna, Dr. Mara Mazzoni and Mrs Maria Grazia Rizzetti in the control experiments for the evaluation of allelic frequencies. 


\section{REFERENCES}

1. Vaccarella S, Franceschi S, Bray F, Wild CP, Plummer M, Dal Maso L 2016 Worldwide Thyroid-Cancer Epidemic? The Increasing Impact of Overdiagnosis. N Engl J Med 375:614-7

2. Dralle H, Machens A, Basa J, Fatourechi V, Franceschi S, Hay ID, Nikiforov YE, Pacini F, Pasieka JL, Sherman SI 2015 Follicular cell-derived thyroid cancer. Nat Rev Dis Primers 10:1-18

3. Acquaviva G, Visani M, Repaci A, Rhoden KJ, de Biase D, Pession A, Giovanni T 2018 Molecular pathology of thyroid tumors of follicular cells: a review of genetic alterations and their clinicopathological relevance. Histopathology 72:6-31

4. Xing M, Alzahrani AS, Carson KA, Shong YK, Kim TY, Viola D, Elisei R, Bendlová B, Yip L, Mian C, Vianello F, Tuttle RM, Robenshtok E, Fagin JA, Puxeddu E, Fugazzola L, Czarniecka A, Jarzab B, O'Neill CJ, Sywak MS, Lam AK, Riesco-Eizaguirre G, Santisteban P, Nakayama H, Clifton-Bligh R, Tallini G, Holt EH, Sýkorová V 2015 Association between BRAF V600E mutation and recurrence of papillary thyroid cancer. J Clin Oncol 33:42-50

5. Henke LE, Pfeifer JD, Ma C, Perkins SM, DeWees T, El-Mofty S, Moley JF, Nussenbaum B, Haughey BH, Baranski TJ, Schwarz JK, Grigsby PW 2015 BRAF mutation is not predictive of long-term outcome in papillary thyroid carcinoma. Cancer Med 4:791-9

6. Vuong HG, Duong UN, Altibi AM, Ngo HT, Pham TQ, Tran HM, Gandolfi G, Hassell L 2017 A meta-analysis of prognostic roles of molecular markers in papillary thyroid carcinoma. Endocr Connect 6: R8-R17

7. Melo M, da Rocha AG, Vinagre J, Batista R, Peixoto J, Tavares C, Celestino R, Almeida A, Salgado C, Eloy C, Castro P, Prazeres H, Lima J, Amaro T, Lobo C, Martins MJ, Moura M, Cavaco B, Leite V, Cameselle-Teijeiro JM, Carrilho F, Carvalheiro M, Máximo V, Sobrinho-Simões M, Soares P 2014 TERT promoter mutations are a major indicator of poor outcome in differentiated thyroid carcinomas. J Clin Endocrinol Metab 99: E754-E765 
8. Muzza M, Colombo C, Rossi S, Tosi D, Cirello V, Perrino M, De Leo S, Magnani E, Pignatti E, Vigo B, Simoni M, Bulfamante G, Vicentini L, Fugazzola L 2015 Telomerase in differentiated thyroid cancer: promoter mutations, expression and localization. Mol Cell Endocrinol 399:288-295

9. Liu R, Xing M 2016 TERT promoter mutations in thyroid cancer. Endocr Relat Cancer 23: R143-55

10. Liu R, Bishop J, Zhu G, Zhang T, Ladenson PW, Xing M 2016 Mortality risk stratification by combining BRAF V600E and TERT promoter mutations in papillary thyroid cancer: genetic duet of BRAF and TERT promoter mutations in thyroid cancer mortality. JAMA Oncol, doi: 10.1001/jamaoncol.2016.3288

11. Moon S, Song YS, Kim YA, Lim JA, Cho SW, Moon JH, Hahn S, Park DJ, Park YJ 2017 Effects of coexistent BRAFV600E and TERT promoter mutations on poor clinical outcomes in papillary thyroid cancer: a meta-analysis. Thyroid 27:651-660

12. Cancer Genome Atlas Research Network 2014 Integrated genomic characterization of papillary thyroid carcinoma. Cell 159:676-690

13. Lu Z, Zhang Y, Feng D, Sheng J, Yang W, Liu B 2017 Targeted next generation sequencing identifies somatic mutations and gene fusions in papillary thyroid carcinoma. Oncotarget 8: 45784-45792

14. Pesenti C, Muzza M, Colombo C, Proverbio MC, Farè C, Ferrero S, Miozzo M, Fugazzola L, Tabano S 2017 MassARRAY-based simultaneous detection of hotspot somatic mutations and recurrent fusion genes in papillary thyroid carcinoma: the PTC-MA assay. Endocrine, doi: 10.1007/s12020-017-1483-2

15. Compton CC, Byrd DR, Garcia-Aguilar J, Kurup P, Kurtzman SH, Olawaiye A, Washington MK 2017 TNM classification of malignant tumors. In AJCC Cancer Staging Handbook 7th Ed Springer Verlag, New York, p.113-120

16. Haugen BR, Sawka AM, Alexander EK, Bible KC, Caturegli P, Doherty GM, Mandel SJ, Morris JC, Nassar A, Pacini F, Schlumberger M, Schuff K, Sherman SI, Somerset H, Sosa JA, Steward DL, Wartofsky L, Williams MD 20162015 American Thyroid Association management guidelines for adult patients with thyroid nodules and differentiated thyroid cancer: the American Thyroid Association guidelines task force on thyroid nodules and differentiated thyroid cancer. Thyroid 26:1-133 
17. Fugazzola L, Puxeddu E, Avenia N, Romei C, Cirello V, Cavaliere A, Faviana P, Mannavola D, Moretti S, Rossi S, Sculli M, Bottici V, Beck-Peccoz P, Pacini F, Pinchera A, Santeusanio F, Elisei R 2006 Correlation between B-RAFV600E mutation and clinico-pathologic parameters in papillary thyroid carcinoma: data from a multicentric Italian study and review of the literature. Endocr Relat Cancer 13:45564

18. Muzza M, Degl'Innocenti D, Colombo C, Perrino M, Ravasi E, Rossi S, Cirello V, BeckPeccoz P, Borrello MG, Fugazzola L 2010 The tight relationship between papillary thyroid cancer, autoimmunity and inflammation: clinical and molecular studies. Clin Endocrinol 72:702-8

19. Pesenti C, Paganini L, Fontana L, Veniani E, Runza L, Ferrero S, Bosari S, Menghi M, Marfia G, Caroli M, Silipigni R, Guerneri S, Tabano S, Miozzo M 2017 Mass spectrometry-based assay for the molecular diagnosis of glioma: concomitant detection of chromosome 1p/19q codeletion, and IDH1, IDH2, and TERT mutation status. Oncotarget 8:57134-57148

20. Tohyama K, Yoshida Y, Ohashi K, Sano E, Kobayashi H, Endo K, Naruto M, Nakamura T 1992 Production of multiple growth factors by a newly established human thyroid carcinoma cell line. Jpn J Cancer Res 83:153-8

21. Nikiforov YE 2017 Role of molecular markers in thyroid nodule management: then and now. Endocr Pract 23:979-988

22. Valerio L, Pieruzzi L, Giani C, Agate L, Bottici V, Lorusso L, Cappagli V, Puleo L, Matrone A, Viola D, Romei C, Ciampi R, Molinaro E, Elisei R. Targeted Therapy in Thyroid Cancer: State of the Art 2017 Clin Oncol (R Coll Radiol) 29:316-324

23. Wang YL, Wang JC, Wu Y, Zhang L, Huang CP, Shen Q, Zhu YX, Li DS, Ji QH 2008 Incidentally simultaneous occurrence of RET/PTC, H4-PTEN and BRAF mutation in papillary thyroid carcinoma. Cancer Lett 263:44-52

24. Guerra A, Zeppa P, Bifulco M, Vitale M 2014 Concomitant BRAF (V600E) mutation and RET/PTC rearrangement is a frequent occurrence in papillary thyroid carcinoma. Thyroid 24:254-259 
25. Henderson YC, Shellenberger TD, Williams MD, El-Naggar AK, Fredrick MJ, Cieply KM, Clayman GL 2009 High rate of BRAF and RET/PTC dual mutations associated with recurrent papillary thyroid carcinoma. Clin Cancer Res 15:485-491

26. Nikiforova MN, Wald Al, Roy S, Durso MB, Nikiforov YE 2013 Targeted nextgeneration sequencing panel (ThyroSeq) for detection of mutations in thyroid cancer. J Clin Endocrinol Metab 98:E1852-60

27. Bedard PL, Hansen AR, Ratain MJ, Siu LL 2013 Tumour heterogeneity in the clinic. Nature 501:355-364

28. Guerra A, Sapio MR, Marotta V, Campanile E, Rossi S, Forno I, Fugazzola L, Budillon A, Moccia T, Fenzi G, Vitale M 2012 The primary occurrence of BRAF (V600E) is a rare clonal event in papillary thyroid carcinoma. J Clin Endocrinol Metab 97:517524

29. De Biase D, Cesari V, Visani M, Casadei GP, Cremonini N, Gandolfi G, Sancisi V, Ragazzi M, Pession A, Ciarrocchi A, Tallini G 2014 High-sensitivity BRAF mutation analysis: BRAF V600E is acquired early during tumor development but is heterogeneously distributed in a subset of papillary thyroid carcinomas. J Clin Endocrinol Metab 99:E1530-8.

30. Sottoriva A, Kang H, Ma Z, Graham TA, Salomon MP, Zhao J, Marjoram P, Siegmund K, Press MF, Shibata D, Curtis C 2015 A Big Bang model of human colorectal tumor growth. Nat Genet 47:209-16

31. Ghossein RA, Katabi N, Fagin JA. 2013 Immunohistochemical detection of mutated BRAF V600E supports the clonal origin of BRAF-induced thyroid cancers along the spectrum of disease progression. J Clin Endocrinol Metab 98: E1414-21

32. Ricarte-Filho JC, Ryder M, Chitale DA, Rivera M, Heguy A, Ladanyi M, Janakiraman M, Solit D, Knauf JA, Tuttle RM, Ghossein RA, Fagin JA 2009 Mutational profile of advanced primary and metastatic radioactive iodine-refractory thyroid cancers reveals distinct pathogenetic roles for BRAF, PIK3CA, and AKT1. Cancer Res 69:4885-4893

33. Romei C, Fugazzola L, Puxeddu E, Frasca F, Viola D, Muzza M, Moretti S, Nicolosi ML, Giani C, Cirello V, Avenia N, Rossi S, Vitti P, Pinchera A, Elisei R 2012 
Modifications in the papillary thyroid cancer gene profile over the last 15 years. J Clin Endocrinol Metab 97:E1758-65

34. Jin L, Chen E, Dong S, Cai Y, Zhang X, Zhou Y, Zeng R, Yang F, Pan C, Liu Y, Wu W, Xing $M$, Zhang $X$, Wang O 2016 BRAF and TERT promoter mutations in the aggressiveness of papillary thyroid carcinoma: a study of 653 patients. Oncotarget 7: $18346-55$

35. Prasad ML, Vyas M, Horne MJ, Virk RK, Morotti R, Liu Z, Tallini G, Nikiforova MN, Christison-Lagay ER, Udelsman R, Dinauer CA, Nikiforov YE 2016 NTRK fusion oncogenes in pediatric papillary thyroid carcinoma in northeast United States. Cancer 122: 1097-107 
Table 1A: Sociodemographic and clinico-pathological characteristics of the papillary thyroid cancer series according to the presence /absence of BRAF, TERT, RAS mutations

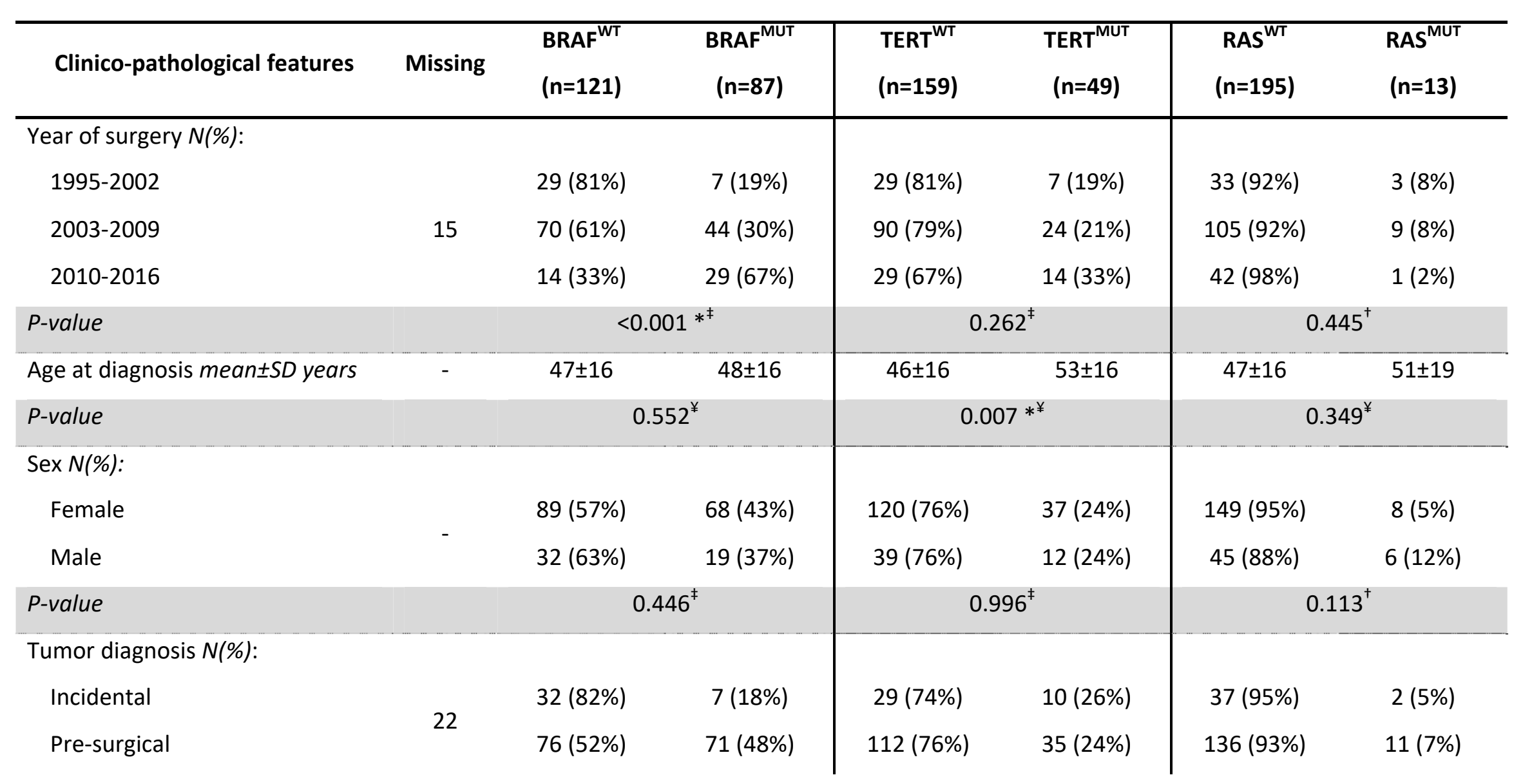




\begin{tabular}{|c|c|c|c|c|c|c|c|}
\hline P-value & & \multicolumn{2}{|c|}{$<0.001 *^{\ddagger}$} & \multicolumn{2}{|c|}{$0.812^{\ddagger}$} & \multicolumn{2}{|c|}{$1.000^{\dagger}$} \\
\hline Tumor size median[IQ] mm & - & $\begin{array}{c}15.00 \\
{[7.00-23.00]}\end{array}$ & $\begin{array}{c}17.00 \\
{[12.00-28.00]}\end{array}$ & $\begin{array}{c}15.00 \\
{[9.00-25.00]}\end{array}$ & $\begin{array}{c}18.00 \\
{[14.00-27.00]}\end{array}$ & $\begin{array}{c}15.00 \\
{[9.00-25.00]}\end{array}$ & $\begin{array}{c}16.00 \\
{[12.00-27.00]}\end{array}$ \\
\hline P-value & & \multicolumn{2}{|c|}{$0.007 * \S$} & \multicolumn{2}{|c|}{$0.054 * * \S$} & \multicolumn{2}{|c|}{$0.636^{\S}$} \\
\hline \multicolumn{8}{|l|}{ Histological variant $N(\%)$ : } \\
\hline СРTC & \multirow{3}{*}{-} & $97(57 \%)$ & $74(43 \%)$ & $135(79 \%)$ & $36(21 \%)$ & $163(95 \%)$ & $8(5 \%)$ \\
\hline FVPTC & & $18(62 \%)$ & $11(38 \%)$ & $19(66 \%)$ & $10(34 \%)$ & $23(79 \%)$ & $6(21 \%)$ \\
\hline $\mathrm{SCL} / \mathrm{COL} / \mathrm{PDTC}$ & & $6(75 \%)$ & $2(25 \%)$ & $5(63 \%)$ & $3(37 \%)$ & $8(100 \%)$ & $0(0 \%)$ \\
\hline P-value & & \multicolumn{2}{|c|}{$0.576^{\dagger}$} & \multicolumn{2}{|c|}{$0.184^{\ddagger}$} & \multicolumn{2}{|c|}{$0.015 *^{\dagger}$} \\
\hline \multicolumn{8}{|l|}{ Extrathyroidal invasion $N(\%)$} \\
\hline Yes & \multirow{2}{*}{-} & $46(50 \%)$ & $46(50 \%)$ & $65(71 \%)$ & $27(29 \%)$ & $87(95 \%)$ & $5(5 \%)$ \\
\hline No & & 75 (65\%) & $41(35 \%)$ & 94 (81\%) & 22 (19\%) & 107 (92\%) & $9(8 \%)$ \\
\hline P-value & & \multicolumn{2}{|c|}{$0.033 *^{\ddagger}$} & \multicolumn{2}{|c|}{$0.080 * *^{\ddagger}$} & \multicolumn{2}{|c|}{$0.507^{\ddagger}$} \\
\hline \multicolumn{8}{|l|}{ Multifocality $N(\%)$} \\
\hline Yes & & $61(59 \%)$ & $43(41 \%)$ & $75(72 \%)$ & $29(28 \%)$ & $98(94 \%)$ & $6(6 \%)$ \\
\hline No & & $60(58 \%)$ & $44(42 \%)$ & $84(81 \%)$ & $20(19 \%)$ & $96(92 \%)$ & $8(8 \%)$ \\
\hline P-value & & \multicolumn{2}{|c|}{$0.882^{\ddagger}$} & \multicolumn{2}{|c|}{$0.141^{\ddagger}$} & \multicolumn{2}{|c|}{$0.580^{\ddagger}$} \\
\hline $\begin{array}{l}\text { TNM } \\
\text { - T N(\%): }\end{array}$ & TNM & & & & & & \\
\hline
\end{tabular}


Page 22 of 52

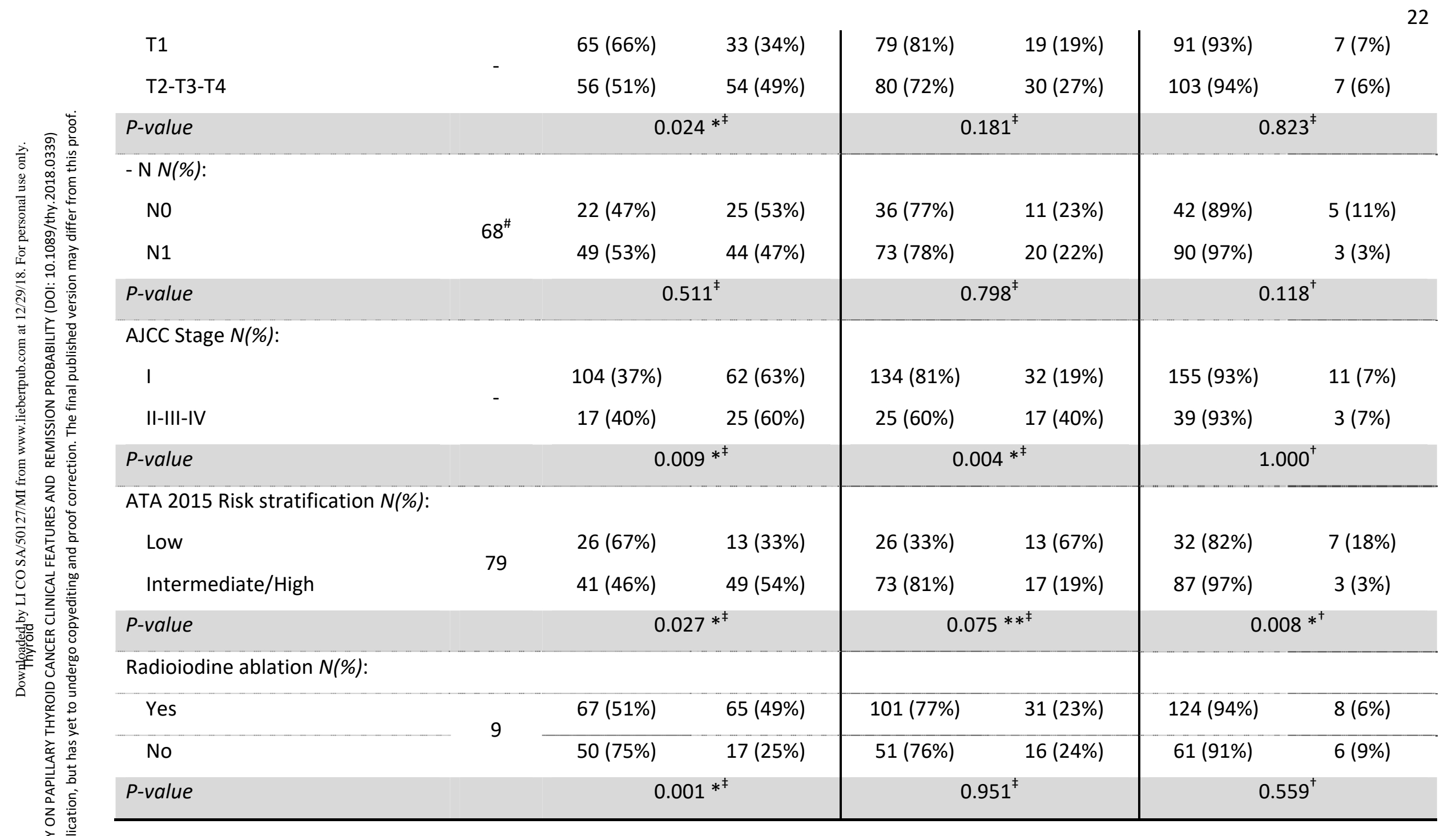


Legend: SD: Standard Deviation; IQ: Interquartile range; CPTC: classical variant PTC; FVPTC: follicular variant PTC; SCL: sclerosing variant; COL: columnar variant; PDTC: poorly differentiated thyroid cancer; AJCC: American Joint Committee on Cancer; ATA: American Thyroid association.

\#Patients not submitted to lymph node removal for whom the $\mathrm{N}$ status is unknown (NX); ¥ Chi square Test; † Fisher Test; ¥ T-test; $\S$ Wilcoxon test; *P-value<0.05; **P-value $<0.10$. 
Table 1B: Sociodemographic and clinico-pathological characteristics of the papillary thyroid cancer series according to the combination of the two genetic events (BRAF and TERT).

\begin{tabular}{|c|c|c|c|c|c|c|}
\hline & & Group & $1(\mathrm{~N}=97)$ & $2(N=62)$ & $3(N=24)$ & $4(N=25)$ \\
\hline \multirow{2}{*}{ Clinico-pathological features } & \multirow{2}{*}{ Missing } & BRAF & WT & MUT & WT & MUT \\
\hline & & TERT & WT & WT & MUT & MUT \\
\hline \multicolumn{7}{|l|}{ Year of surgery $N(\%):$} \\
\hline $1995-2002$ & \multirow{2}{*}{15} & & $24(67 \%)$ & $5(14 \%)$ & $5(14 \%)$ & $2(5 \%)$ \\
\hline $2010-2016$ & & & $11(6 \%)$ & $18(42 \%)$ & $3(7 \%)$ & $11(25 \%)$ \\
\hline P-value & & & \multicolumn{4}{|c|}{$0.001 *^{+}$} \\
\hline Age at diagnosis mean $\pm S D$ years & - & & $47 \pm 16$ & $45 \pm 15$ & $48 \pm 15$ & $57 \pm 16$ \\
\hline P-value & & & \multicolumn{4}{|c|}{$0.007^{* *}$} \\
\hline P-value & & & \multicolumn{4}{|c|}{$0.613^{\ddagger}$} \\
\hline \multicolumn{7}{|l|}{ Tumor diagnosis $N(\%)$ : } \\
\hline Incidental & 22 & & $25(64 \%)$ & $4(10 \%)$ & $7(18 \%)$ & $3(8 \%)$ \\
\hline
\end{tabular}




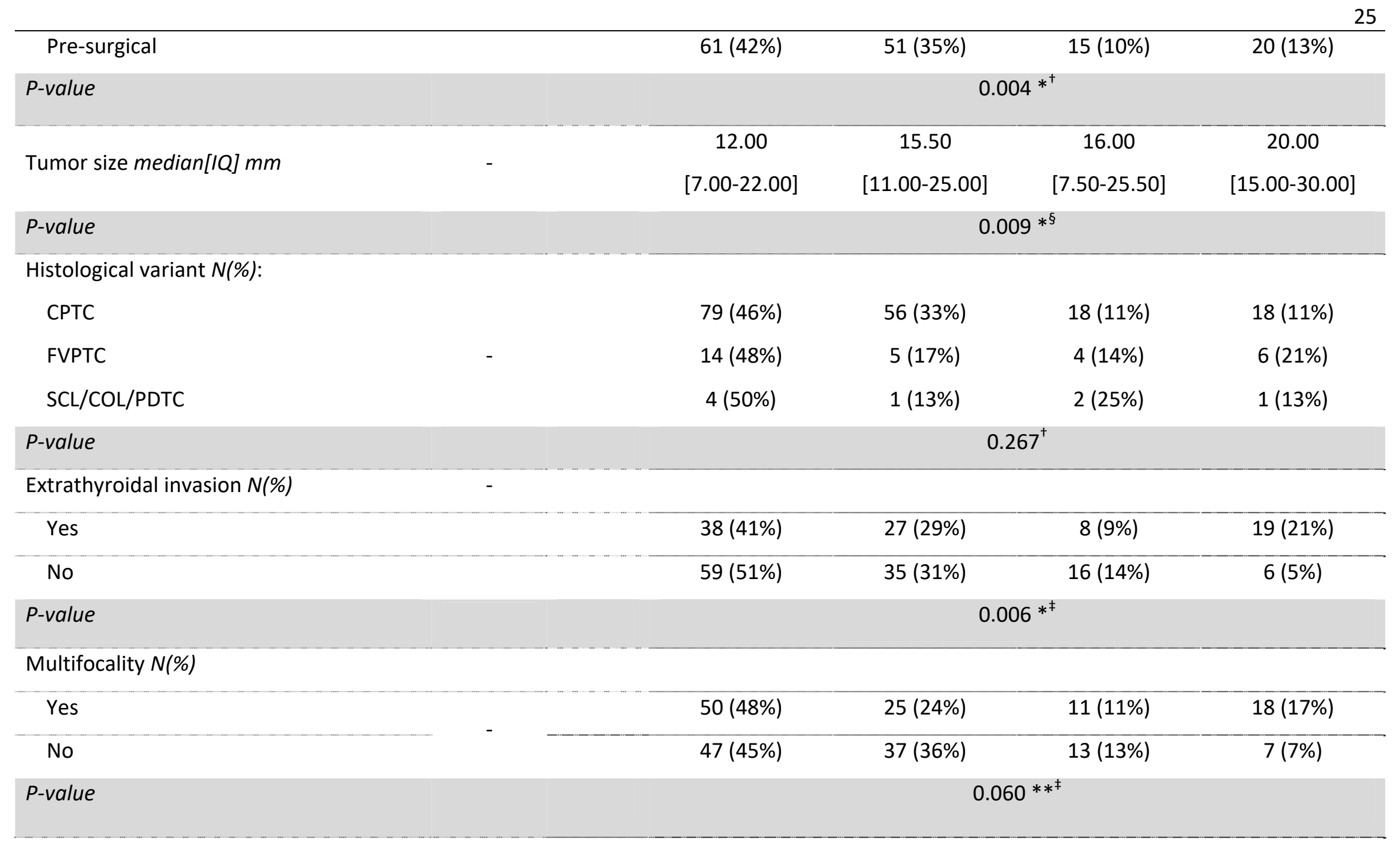


Page 26 of 52

\section{TNM}

- T N(\%):

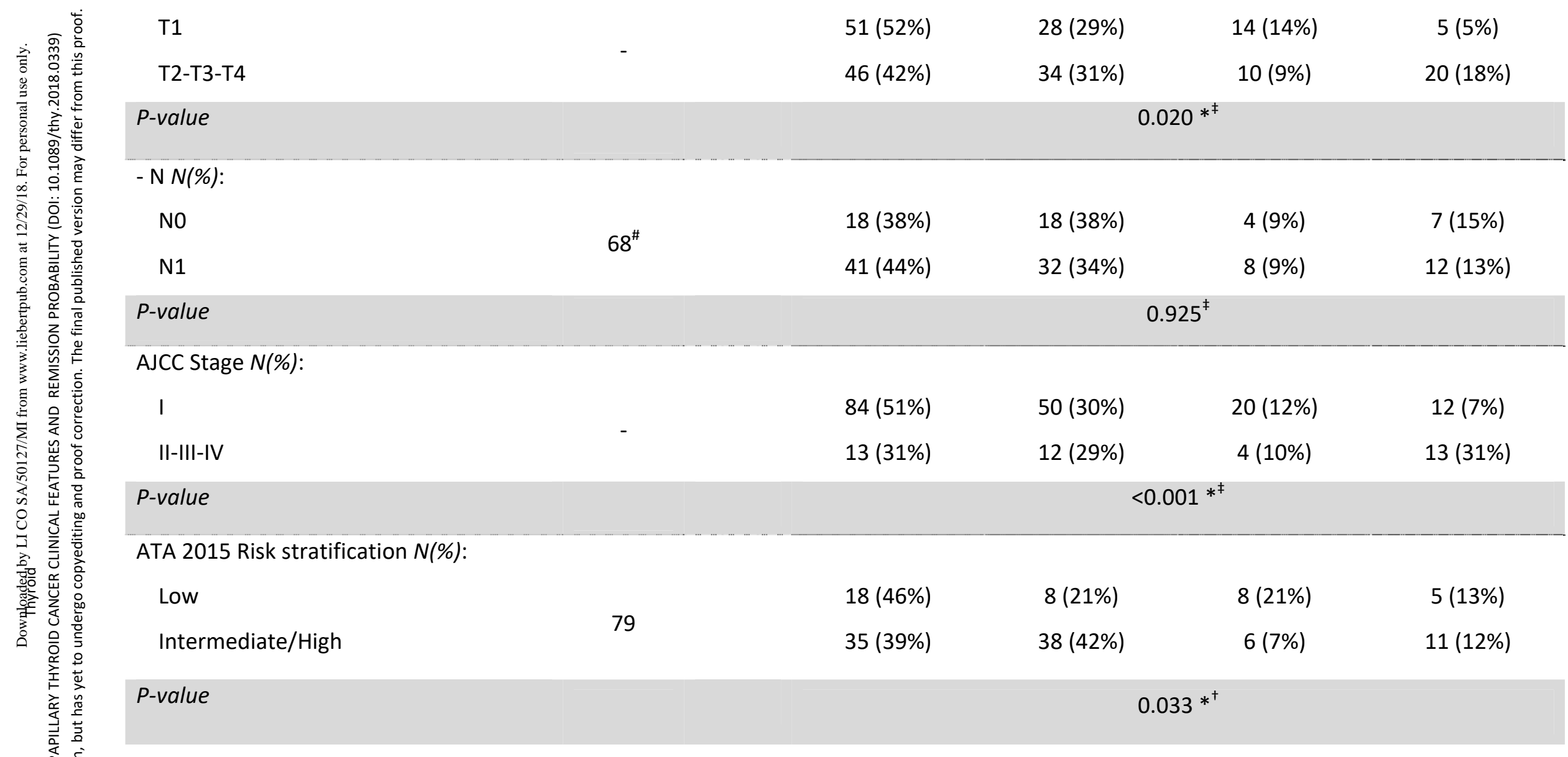




\section{Radioiodine ablation $N(\%)$ :}

Yes

No

P-value
$56(42 \%)$

$38(57 \%)$
45 (34\%)

$13(19 \%)$
$11(8 \%)$

$12(18 \%)$

$20(15 \%)$

\subsection{8 *}

Legend: SD: Standard Deviation; IQ: Interquartile range; CPTC: classical variant PTC; FVPTC: follicular variant PTC; SCL: Sclerosing variant; COL: columnar variant; PDTC: poorly differentiated thyroid cancer; AJCC: American Joint Committee on Cancer; ATA: American Thyroid association. \#Patients not submitted to lymph nodal removal for whom the N status is unknown (NX); ¥ Chi square Test; † Fisher Test; ¥ T-test; § Wilcoxon test; *P-value<0.05; **P-value<0.10. 
Page 28 of 52

Table 1C: Sociodemographic and clinico-pathological characteristics of the papillary thyroid cancer series according to the presence /absence of RET and TRK fusions.

\begin{tabular}{|c|c|c|c|c|c|}
\hline Clinico-pathological features & Missing & $\begin{array}{c}\mathrm{ret} / \mathrm{PTC}^{\mathrm{WT}} \\
(\mathrm{n}=171)\end{array}$ & $\begin{array}{c}\text { ret/PTC } \\
(n=37)\end{array}$ & $\begin{array}{c}\text { TRK }^{W T} \\
(n=203)\end{array}$ & $\begin{array}{c}\text { TRK }^{\mathrm{MUT}} \\
(n=5)\end{array}$ \\
\hline \multicolumn{6}{|l|}{ Year of surgery $N(\%)$ : } \\
\hline 1995-2002 & & $25(69 \%)$ & $11(31 \%)$ & $35(97 \%)$ & $1(3 \%)$ \\
\hline 2003-2009 & 15 & $95(83 \%)$ & $19(17 \%)$ & $113(99 \%)$ & $1(1 \%)$ \\
\hline $2010-2016$ & & $37(86 \%)$ & $6(14 \%)$ & $40(93 \%)$ & $3(7 \%)$ \\
\hline P-value & & \multicolumn{2}{|c|}{$0.117^{\ddagger}$} & \multicolumn{2}{|c|}{$0.100 * *^{\ddagger}$} \\
\hline Age at diagnosis mean $\pm S D$ years & - & $48 \pm 16$ & $44 \pm 17$ & $48 \pm 16$ & $28 \pm 10$ \\
\hline P-value & & \multicolumn{2}{|c|}{$0.132^{¥}$} & \multicolumn{2}{|c|}{$0.007 * *$} \\
\hline \multicolumn{6}{|l|}{$\operatorname{Sex} N(\%)$} \\
\hline Female & \multirow{2}{*}{ - } & $131(83 \%)$ & $26(17 \%)$ & $156(99 \%)$ & $1(1 \%)$ \\
\hline Male & & $40(78 \%)$ & $11(22 \%)$ & $47(92 \%)$ & $4(8 \%)$ \\
\hline P-value & & \multicolumn{2}{|c|}{$0.417^{\ddagger}$} & \multicolumn{2}{|c|}{$0.014 *^{+}$} \\
\hline \multicolumn{6}{|l|}{ Tumor diagnosis $N(\%)$ : } \\
\hline Incidental & \multirow[t]{2}{*}{22} & $34(87 \%)$ & $5(13 \%)$ & 39 (100\%) & $0(0 \%)$ \\
\hline Pre-surgical & & 116 (79\%) & $31(21 \%)$ & 142 (97\%) & $5(3 \%)$ \\
\hline
\end{tabular}




\begin{tabular}{|c|c|c|c|c|c|}
\hline P-value & & \multicolumn{2}{|c|}{$0.245^{\ddagger}$} & \multicolumn{2}{|c|}{$0.586^{\dagger}$} \\
\hline Tumor size median[IQ] mm & - & $\begin{array}{c}15.00 \\
{[8.00-25.00]}\end{array}$ & $\begin{array}{c}19.00 \\
{[12.00-27.00]}\end{array}$ & $\begin{array}{c}15.00 \\
{[9.00-25.00]}\end{array}$ & $\begin{array}{c}23.00 \\
{[20.00-28.00]}\end{array}$ \\
\hline P-value & & \multicolumn{2}{|c|}{$0.063 * * \S$} & \multicolumn{2}{|c|}{$0.123^{\S}$} \\
\hline \multicolumn{6}{|l|}{ Histological variant $N(\%)$ : } \\
\hline СРTC & \multirow{3}{*}{-} & $142(83 \%)$ & $29(17 \%)$ & $166(97 \%)$ & $5(3 \%)$ \\
\hline FVPTC & & $23(79 \%)$ & $6(21 \%)$ & $29(100 \%)$ & $0(0 \%)$ \\
\hline $\mathrm{SCL} / \mathrm{COL} / \mathrm{PDTC}$ & & $6(75 \%)$ & $2(25 \%)$ & $8(100 \%)$ & $0(0 \%)$ \\
\hline P-value & & \multicolumn{2}{|c|}{$0.767^{\ddagger}$} & \multicolumn{2}{|c|}{$1.000^{\dagger}$} \\
\hline \multicolumn{6}{|l|}{ Extrathyroidal Invasion $N(\%)$} \\
\hline Yes & \multirow{2}{*}{-} & $71(77 \%)$ & $21(23 \%)$ & $88(96 \%)$ & $4(4 \%)$ \\
\hline No & & $100(86 \%)$ & $16(14 \%)$ & $115(99 \%)$ & $1(1 \%)$ \\
\hline P-value & & \multicolumn{2}{|c|}{$0.091 * *^{\ddagger}$} & \multicolumn{2}{|c|}{$0.173^{\dagger}$} \\
\hline \multicolumn{6}{|l|}{ Multifocality $N(\%)$} \\
\hline Yes & & $86(83 \%)$ & $18(17 \%)$ & $103(99 \%)$ & $1(1 \%)$ \\
\hline No & & $85(82 \%)$ & $19(18 \%)$ & $100(96 \%)$ & $4(4 \%)$ \\
\hline P-value & & \multicolumn{2}{|c|}{$0.856^{\ddagger}$} & \multicolumn{2}{|c|}{$0.369^{+}$} \\
\hline $\begin{array}{l}\text { TNM } \\
\text { - T N(\%): }\end{array}$ & & & & & \\
\hline
\end{tabular}


Legend: SD: Standard Deviation; IQ: Interquartile range; CPTC: classical variant PTC; FVPTC: follicular variant PTC; SCL: Sclerosing variant; COL: columnar variant; PDTC: poorly differentiated thyroid cancer; AJCC: American Joint Committee on Cancer; ATA: American Thyroid association.

\#Patients not submitted to lymph nodal removal for whom the N status is unknown (NX); ¥ Chi square Test; † Fisher Test; ¥ T-test; $\S$ Wilcoxon test; *P-value<0.05; **P-value<0.10. 
Page 32 of 52

Table 2: Sociodemographic and clinico-pathological characteristics of the papillary thyroid cancer series according $\leq 1$ or $\geq 2$ genetic events

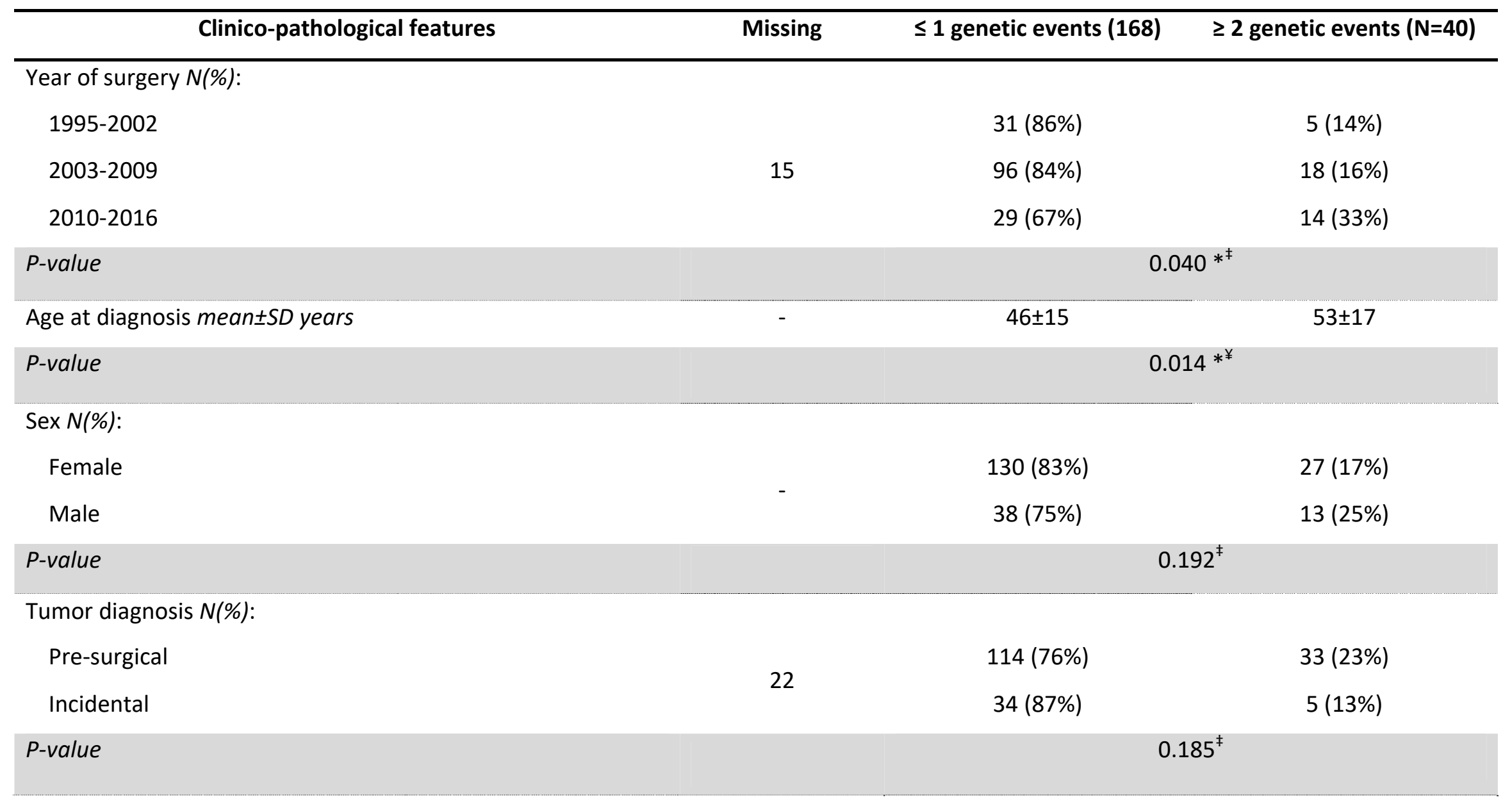


Page 33 of 52

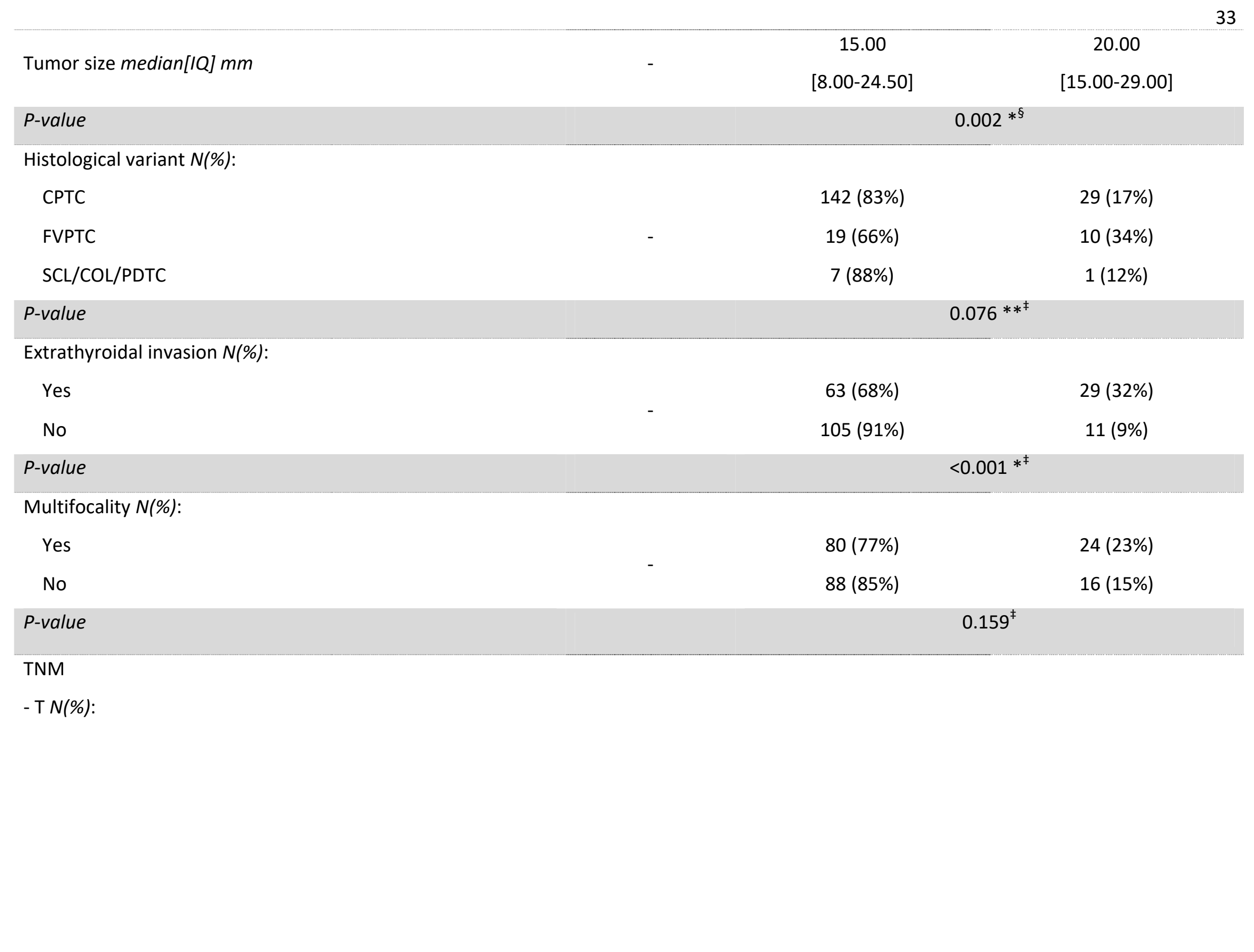


Page 34 of 52

T1

T2-T3-T4

P-value

- N N(\%):

NO

N1

P-value

AJCC Stage $N(\%)$ :

I

II-III-IV

P-value

ATA 2015 Risk stratification N(\%):

Low

Intermediate/High

P-value

Radioiodine ablation $N(\%)$ :

Yes

No

P-value
89 (91\%)

79 (72\%)

$<0.001 *^{\ddagger}$

$68^{\#}$

37 (79\%)

$10(21 \%)$

$71(76 \%)$

$22(24 \%)$

$0.752^{\ddagger}$

$142(86 \%)$

$24(14 \%)$

$26(62 \%)$

$16(38 \%)$

$<0.001 *^{\ddagger}$

79

$\begin{array}{lc}69(77 \%) & 21(23 \%) \\ 31(80 \%) & 8(21 \%)\end{array}$

$0.725^{\ddagger}$

101 (77\%)

$31(23 \%)$

59 (88\%)

8 (12\%)
34

$31(28 \%)$ 
Legend: SD: Standard Deviation; IQ: Interquartile range; CPTC: classical variant PTC; FVPTC: follicular variant PTC; SCL: Sclerosing variant; COL: columnar variant; PDTC: poorly differentiated thyroid cancer; AJCC: American Joint Committee on Cancer; ATA: American Thyroid association.

\#Patients not submitted to lymph nodal removal for whom the N status is unknown (NX); ¥ Chi square Test; † Fisher Test; ¥ T-test; $\S$ Wilcoxon test; *P-value<0.05; **P-value<0.10. 


\section{LEGENDS TO FIGURES}

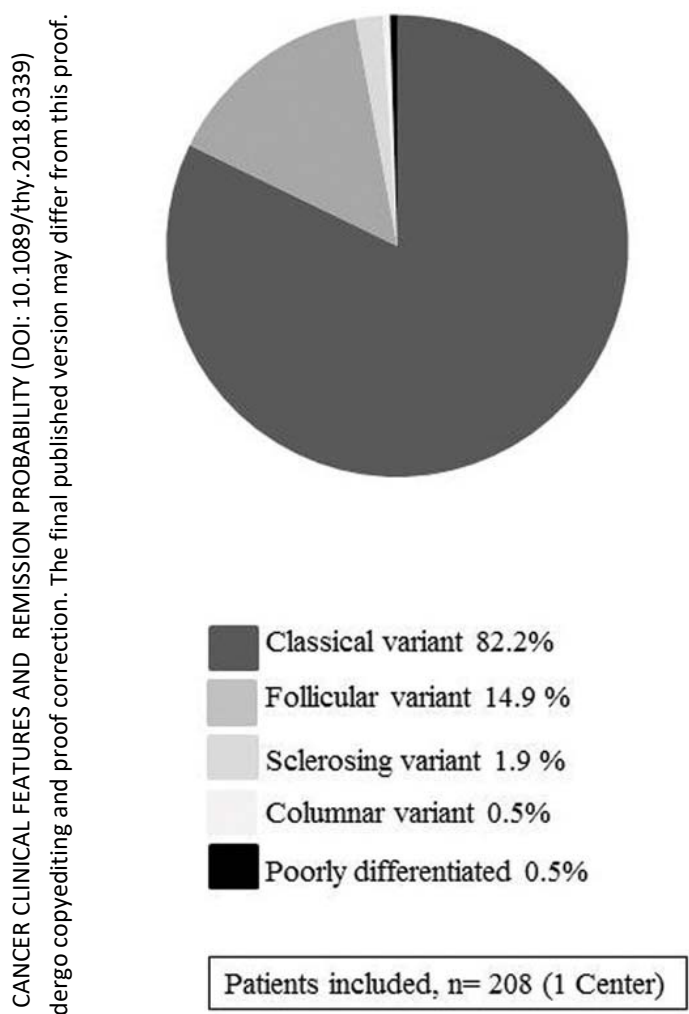

\begin{tabular}{|c|c|c|}
\hline $\begin{array}{l}\text { Sample } \\
\text { analyzed }\end{array}$ & $\begin{array}{l}\text { Multiplexed PCR } \\
\text { (Mix ID) }\end{array}$ & $\begin{array}{c}\text { mutation/fusion } \\
\text { detectable }\end{array}$ \\
\hline \multirow{9}{*}{$\begin{array}{c}\text { GENOMIC } \\
\text { DNA }\end{array}$} & 1 & BRAF_V600E \\
\hline & 1 & AKT1_E17K \\
\hline & 1 & EIF1AX_c338-1GtoC \\
\hline & 1 & NRAS_Q61R \\
\hline & 1 & NRAS_Q61K \\
\hline & 1 & HRAS_Q61K \\
\hline & 1 & HRAS_Q61R \\
\hline & 1 & TERT_c.-124 C > T (G228A) \\
\hline & 1 & TERT_c.-146C $>$ T (G250A) \\
\hline \multirow{6}{*}{ cDNA } & 2 & HRAS_G13C \\
\hline & 2 & KRAS_G12V \\
\hline & 2 & RET_PTC1 \\
\hline & 2 & RET_PTC3 \\
\hline & 2 & TRK \\
\hline & 2 & TRK_T1 \\
\hline \multirow{4}{*}{ cDNA } & 3 & PIK3CA_E542K \\
\hline & 3 & RET_PTC2 \\
\hline & 3 & KRAS_G13C \\
\hline & 3 & TRK_T3 \\
\hline
\end{tabular}

Figure 1: Histological variants of the analyzed papillary thyroid carcinomas and their relative frequencies (left). List of the mutations/fusions detectable by PTC-MA assay divided according to the multiplexed PCR and the starting material used (right). 


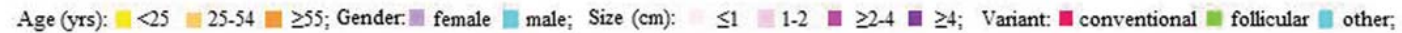

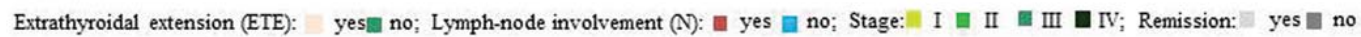

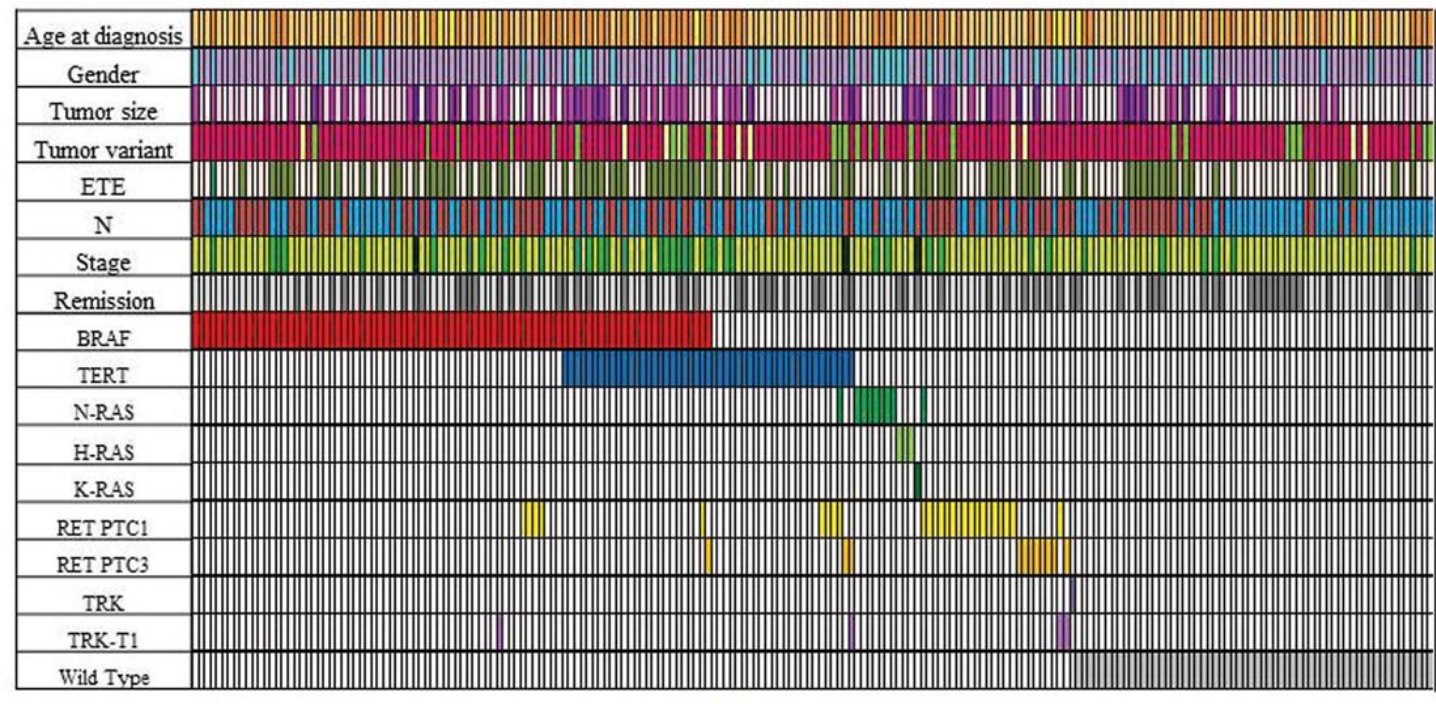

BRAF $^{\mathrm{V} 600 \mathrm{E}}$ 42\%;

Figure 2: Detailed description of patient demographics and point mutations/fusions landscape of 208 cases of papillary thyroid carcinoma. Colored rectangles indicate mutation categories observed in a given gene and the corresponding clinico-pathological features. The percentages of cases mutated for a given gene are reported at the bottom of the Figure. 
A

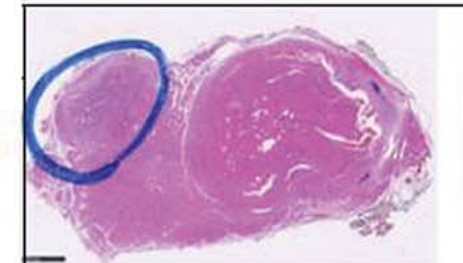

$\mathrm{Pt}$ 94: classical variant PTC, $7 \mathrm{~mm}$; pT1NX
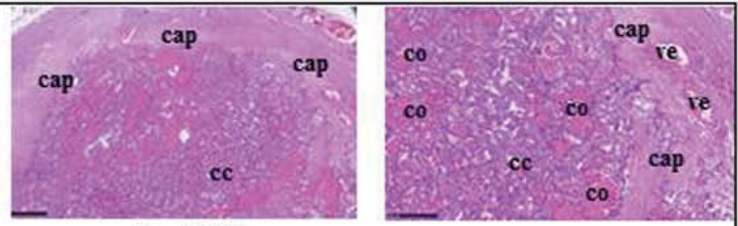

cancer cells: $20 \%$

TERT ${ }^{\mathrm{G} 228 \mathrm{~A}}$, allelic frequency: $4 \%$ normalized allelic frequency: $20 \%$

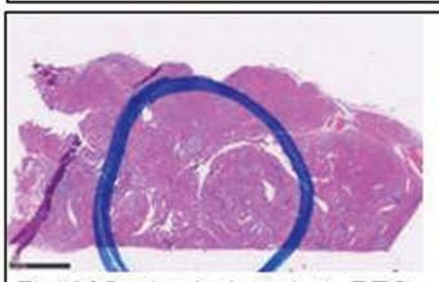

Pt \#105: classical variant PTC + thyroiditis, $7 \mathrm{~mm}$; pT1NX

cancer cells: $10 \%$
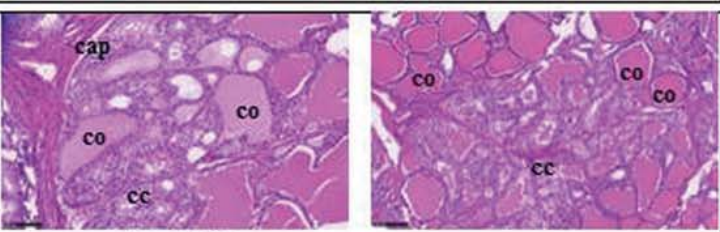

TERT ${ }^{\mathrm{G} 228 \mathrm{~A}}$, allelic frequency $8 \%$

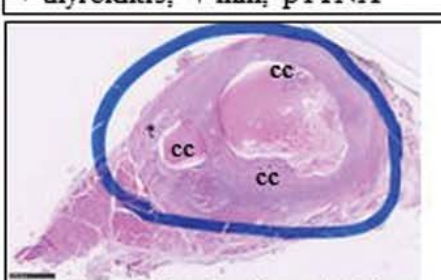
normalized allelic frequency: $80 \%$

$\mathrm{Pt} \# 28$ : classical variant $\mathrm{PTC}$, $12 \mathrm{~mm}$; pT1NX
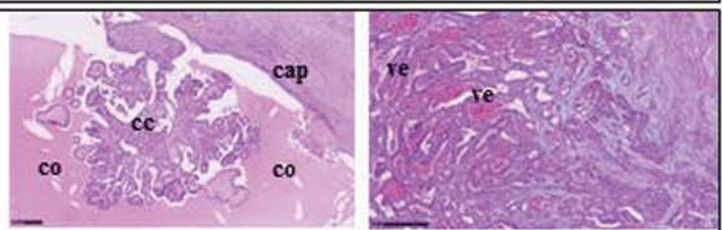

cancer cells: $20 \%$

$\mathrm{BRAF}^{\mathrm{V} 600 \mathrm{E}}$, allelic frequency: $14 \%$ normalized allelic frequency: $70 \%$

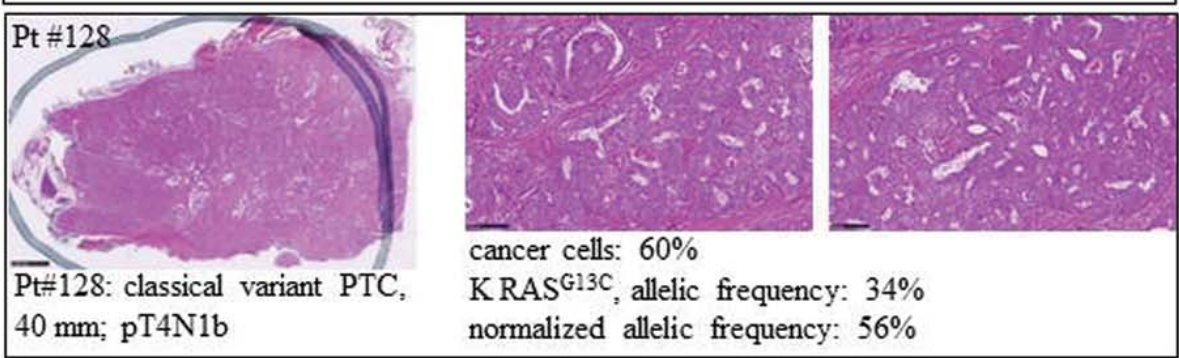

B
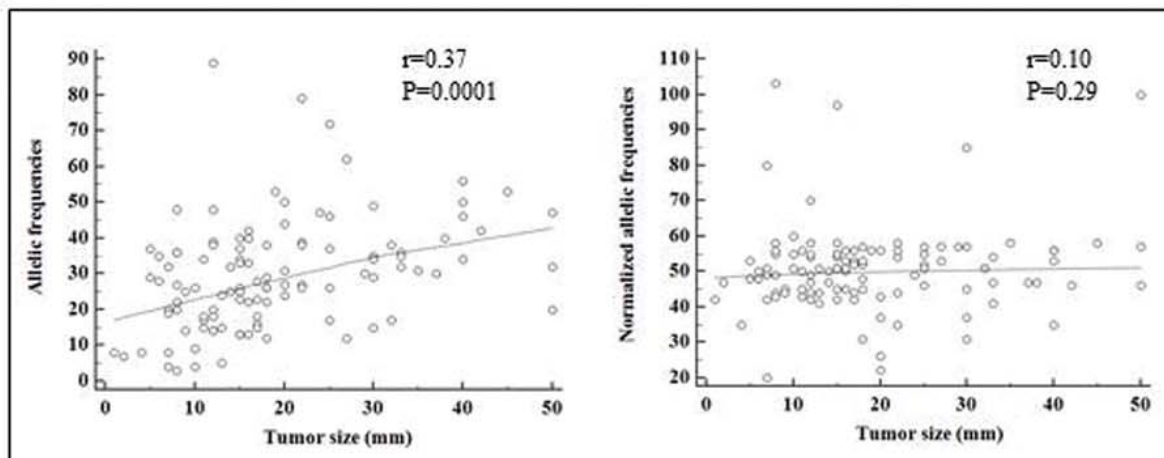

Figure 3: Panel A: Representative thyroid tumor tissues by histology (H\&E staining). The pen lines on the left side of the Figure indicate the parts that have been cut on the paraffin embedded blocks. The right side of the Figure reports parts of the section highlighted in blue, at higher magnification. For each case clinical and genetic features are reported. The 
proportion of cancer cells (cc) was obtained after careful microscopic evaluation of the area marked on the hematoxylin and eosin slide by two pathologists (G.B. and S.R.), who were blinded to the results of the mutational analysis. In particular, the mean percentage of cancer cells was calculated in each sample by looking at 100 cells in 4 fields at $40 \mathrm{X}$ magnification. For each field, the number of tumor cells per 100 cells were counted and a mean of the results obtained in the 4 fields was obtained. Due to the small size of the tumor (Pt\#94) and to the presence of separated microfoci (Pt\#28), microdissected material included a large part of non-neoplastic cells: capsule (cap), vessels (ve), thyroid colloid (co). In larger tumors (Pt\#128), the microdissected tissue was composed mostly, but not entirely, by cancer cells, since endothelial cells and a little fibrotic area can be identified. Indeed, even in a tumor tissue which appears to consist predominantly of cancer cells, cancer cells are diluted by the increased number of vessels; Panel B: Correlation between crude frequencies of mutated alleles and tumor size $(P=0.0001)$, and between normalized frequencies of mutated alleles and tumor size $(P=0.29)$. 


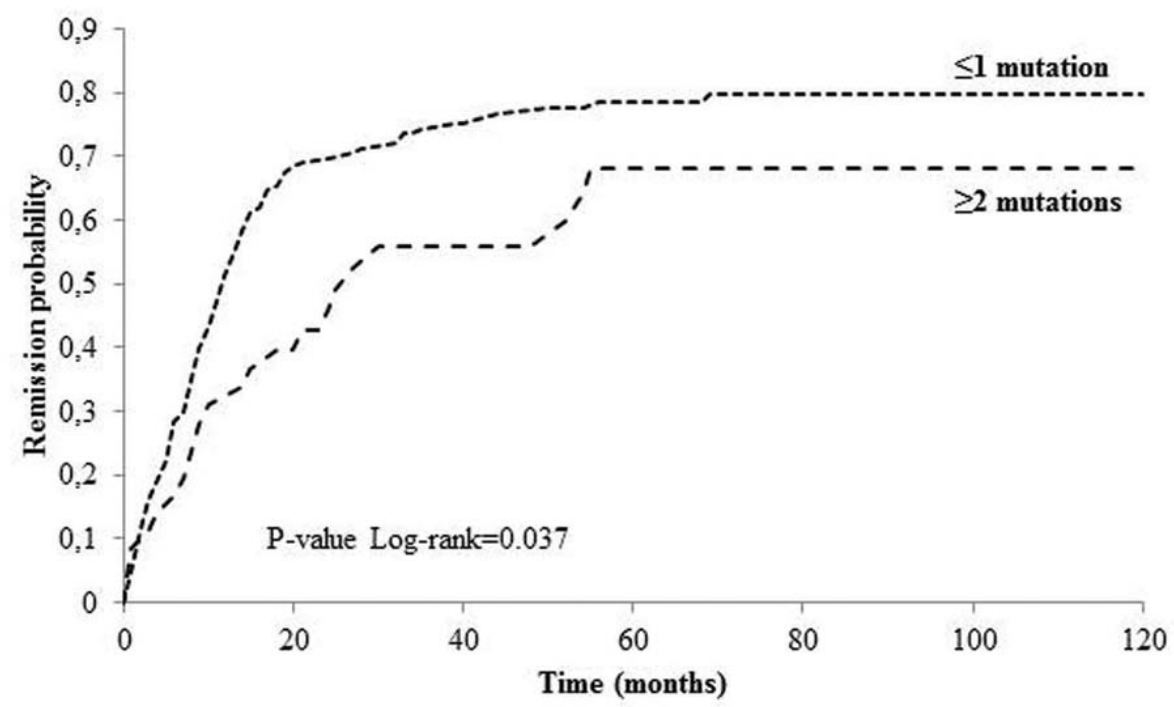

Patients at risk

\begin{tabular}{|l|c|c|c|c|c|c|c|}
\hline$\leq 1$ mutation & 149 & 44 & 31 & 20 & 17 & 16 & 15 \\
\hline$\geq 2$ mutations & 36 & 20 & 12 & 8 & 8 & 7 & 3 \\
\hline
\end{tabular}

Figure 4: Survival curves by mutation density (dichotomized as $\leq 1$ or $\geq 2$ mutations) examined by Kaplan-Meier analyses with log-rank test, censoring patients at the time of patient remission or, in the case of absent remission, at the time of last clinical contact. 
41

Supplemental Table 1: Sociodemographic and clinico-pathological features of the PTC series

\begin{tabular}{|c|c|c|}
\hline Features & Missing & PTCs series (208) \\
\hline Age at Diagnosis, mean $\pm S D$ (range) years & - & $47.4 \pm 16.1(14-88)$ \\
\hline \multicolumn{3}{|l|}{ Gender $N(\%)$} \\
\hline Female & & $157(75 \%)$ \\
\hline Male & & $51(25 \%)$ \\
\hline \multicolumn{3}{|l|}{ Tissue Type N(\%) } \\
\hline Frozen & & $104(50 \%)$ \\
\hline FFPE & & $104(50 \%)$ \\
\hline \multicolumn{3}{|l|}{ Tumor diagnosis $N(\%)$} \\
\hline Pre-surgical & \multirow{2}{*}{$22(11 \%)$} & $147(71 \%)$ \\
\hline Incidental & & 39 (19\%) \\
\hline Tumor size, mean $\pm S D$ (range) $\mathrm{mm}$ & - & $19.0 \pm 13.7(1-90)$ \\
\hline \multicolumn{3}{|l|}{ Histological Variant N(\%) } \\
\hline СРТC & & $171(82 \%)$ \\
\hline FVPTC & & $29(14 \%)$ \\
\hline Sclerosant & - & $6(3 \%)$ \\
\hline Columnar & & $1(0.5 \%)$ \\
\hline PDTC & & $1(0.5 \%)$ \\
\hline \multicolumn{3}{|l|}{ Extrathyroid Invasion N(\%) } \\
\hline No & & $116(56 \%)$ \\
\hline Yes & - & $92(44 \%)$ \\
\hline \multicolumn{3}{|l|}{ Multifocality $N(\%)$} \\
\hline No & & $104(50 \%)$ \\
\hline Yes & & $104(50 \%)$ \\
\hline \multicolumn{3}{|l|}{$\mathrm{T} N(\%)$} \\
\hline $\mathrm{T} 1$ & - & $98(47 \%)$ \\
\hline
\end{tabular}




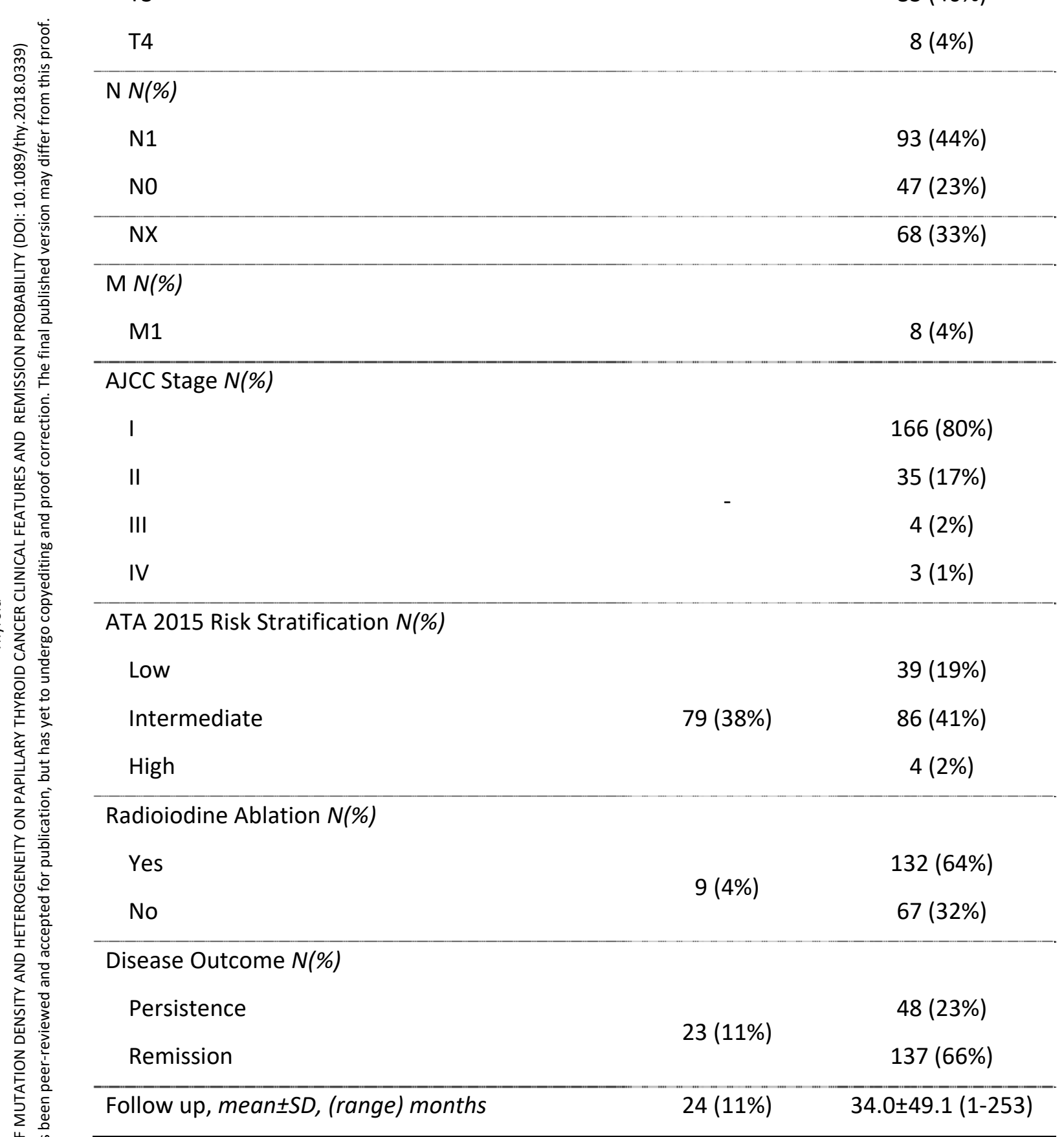

Legend: SD: Standard Deviation; CPTC: classical variant PTC; FVPTC: follicular variant PTC; FFPE: formalin fixed paraffin embedded; AJCC: American Joint Committee on Cancer; ATA: American Thyroid Association 
Supplemental Table 2: data on the percentage of cancer cells, of mutated and normal alleles at PTC-MA assay. The allelic frequency normalized for the percentage of cancer cells is also reported. Only the tumors with at least 1 point mutation have been included ( $n=123$ ). The allelic frequency for fusion genes cannot be evaluated since their detection involve a selective amplification of the rearranged gene transcript. Cases are reported from the lower to the highest normalized allelic frequency. Normalized allelic frequencies of $50 \% \pm 8 \%$ (light grey) are consistent with the presence of the heterozygous mutation in all the cancer cells, lower normalized allelic frequencies (white) are consistent with the presence of the mutations in a small subset of cancer cells. Another subset of less than 10 cases showed an allelic frequency higher than $58 \%$, possibly indicating a clonal event plus deletion of the wild type allele (darker grey).

\begin{tabular}{|c|c|c|c|c|c|c|c|}
\hline Pt\# & $\begin{array}{c}\text { Cancer cells } \\
\text { (\%) }\end{array}$ & \multicolumn{2}{|c|}{ BRAF } & \multicolumn{2}{|c|}{ TERT } & \multicolumn{2}{|c|}{ RAS } \\
\hline 95 & 81 & & & $5 / 95$ & 3 & & \\
\hline 73 & 95 & $50 / 50$ & 53 & $20 / 80$ & 21 & & \\
\hline 68 & 98 & $22 / 78$ & 22 & $50 / 50$ & 51 & & \\
\hline 109 & 95 & & & $53 / 47$ & 56 & $24 / 76$ & 25 \\
\hline
\end{tabular}


Page 44 of 52

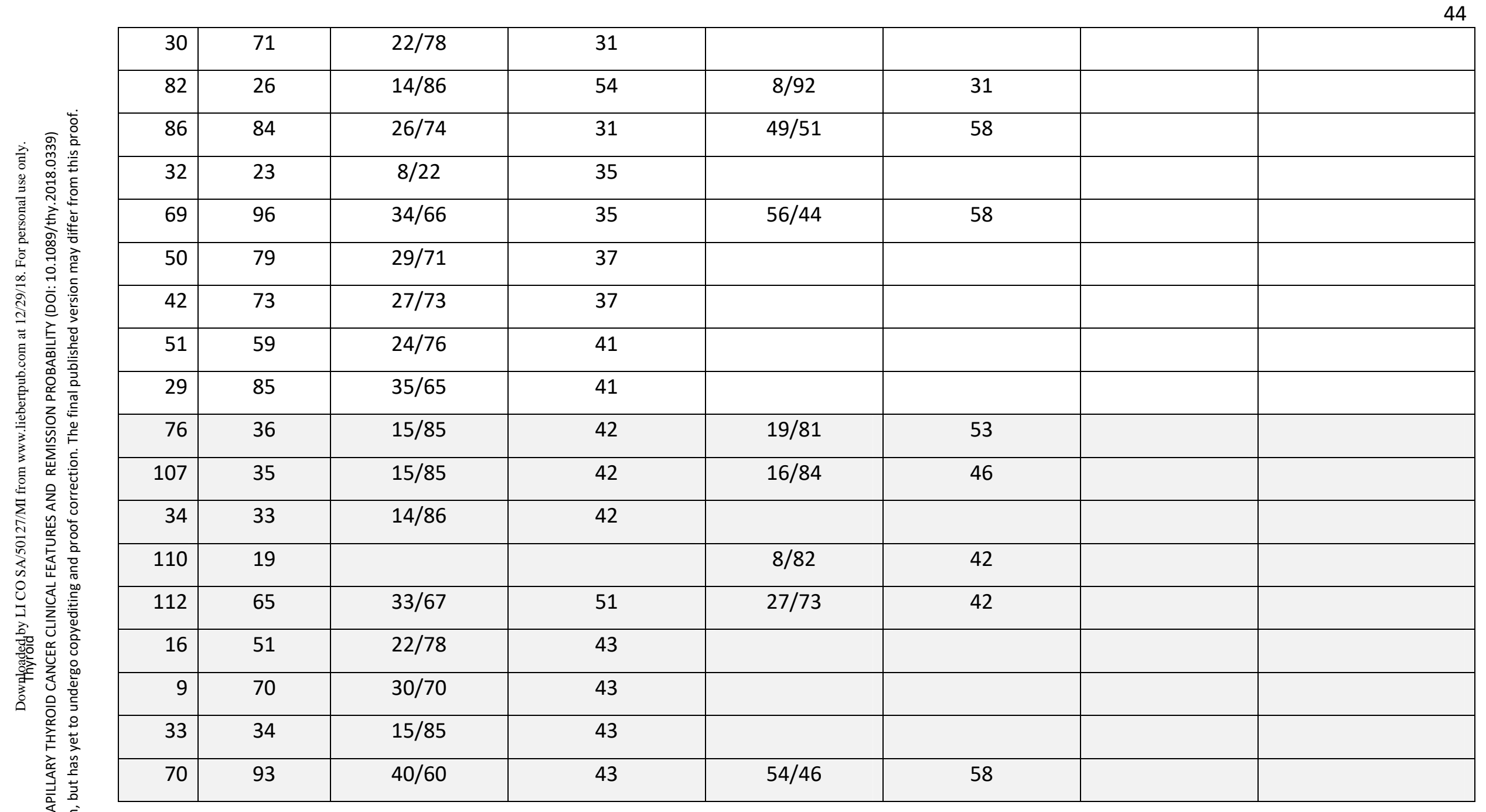




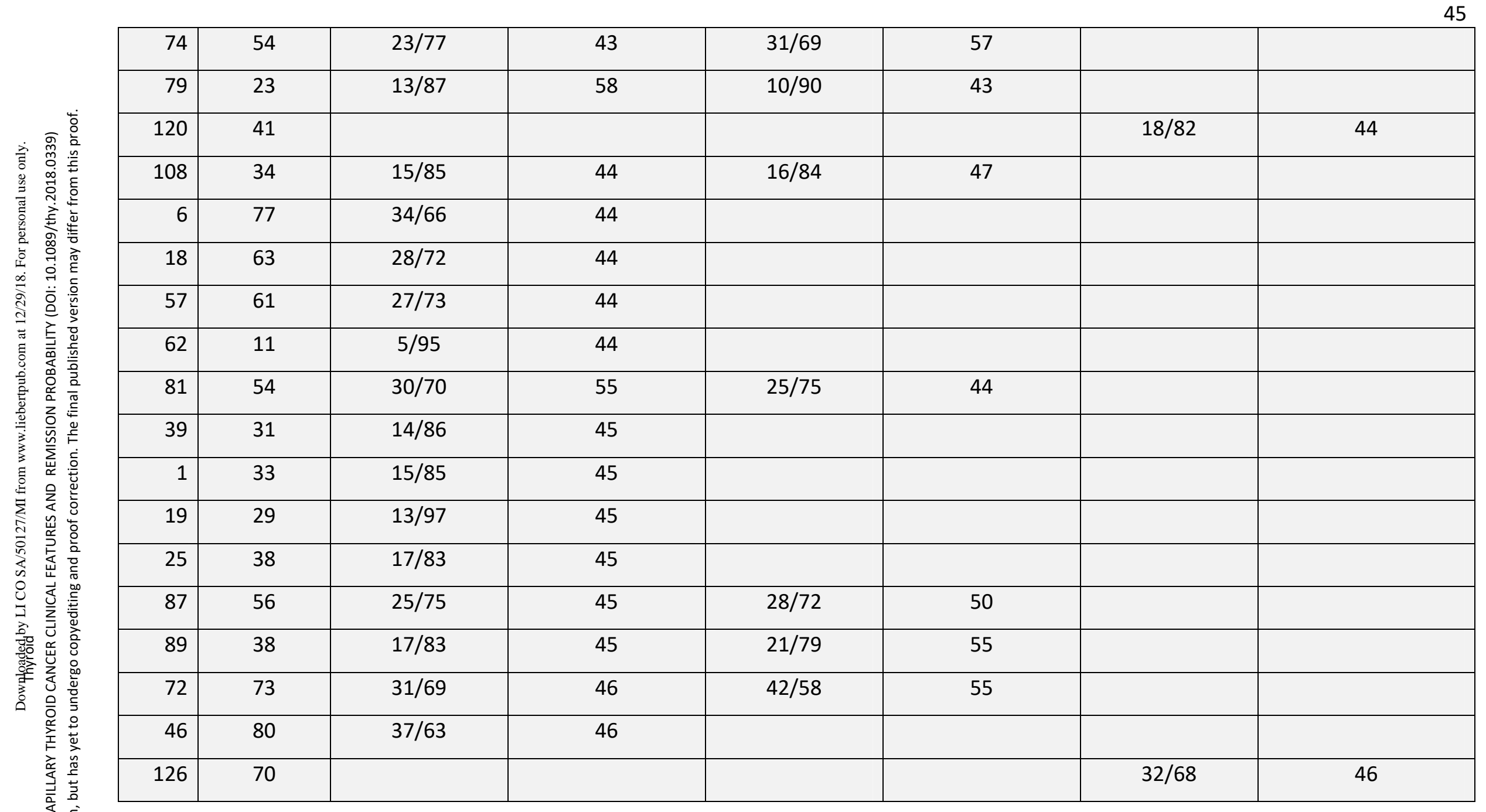


Page 46 of 52

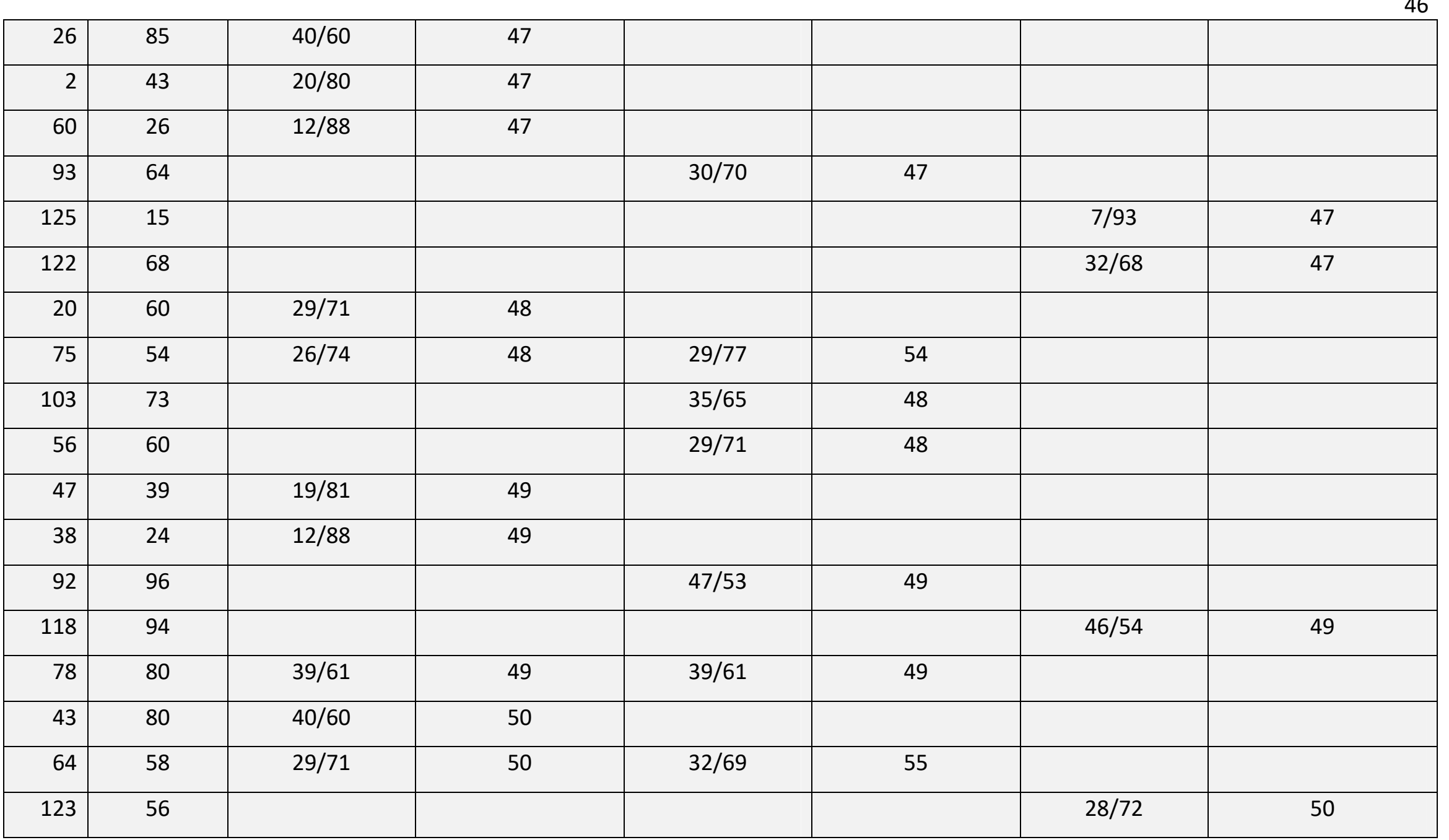




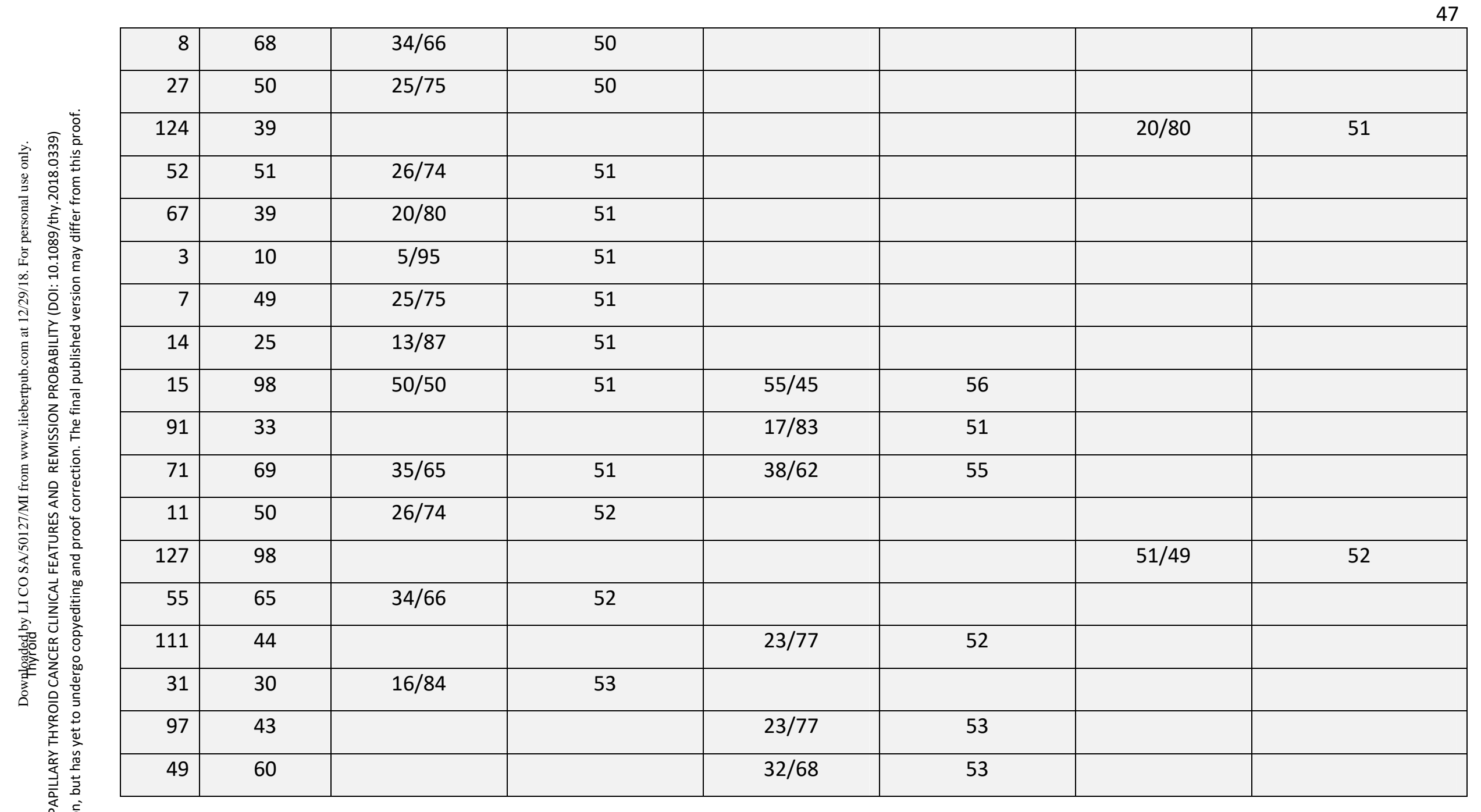


Page 48 of 52

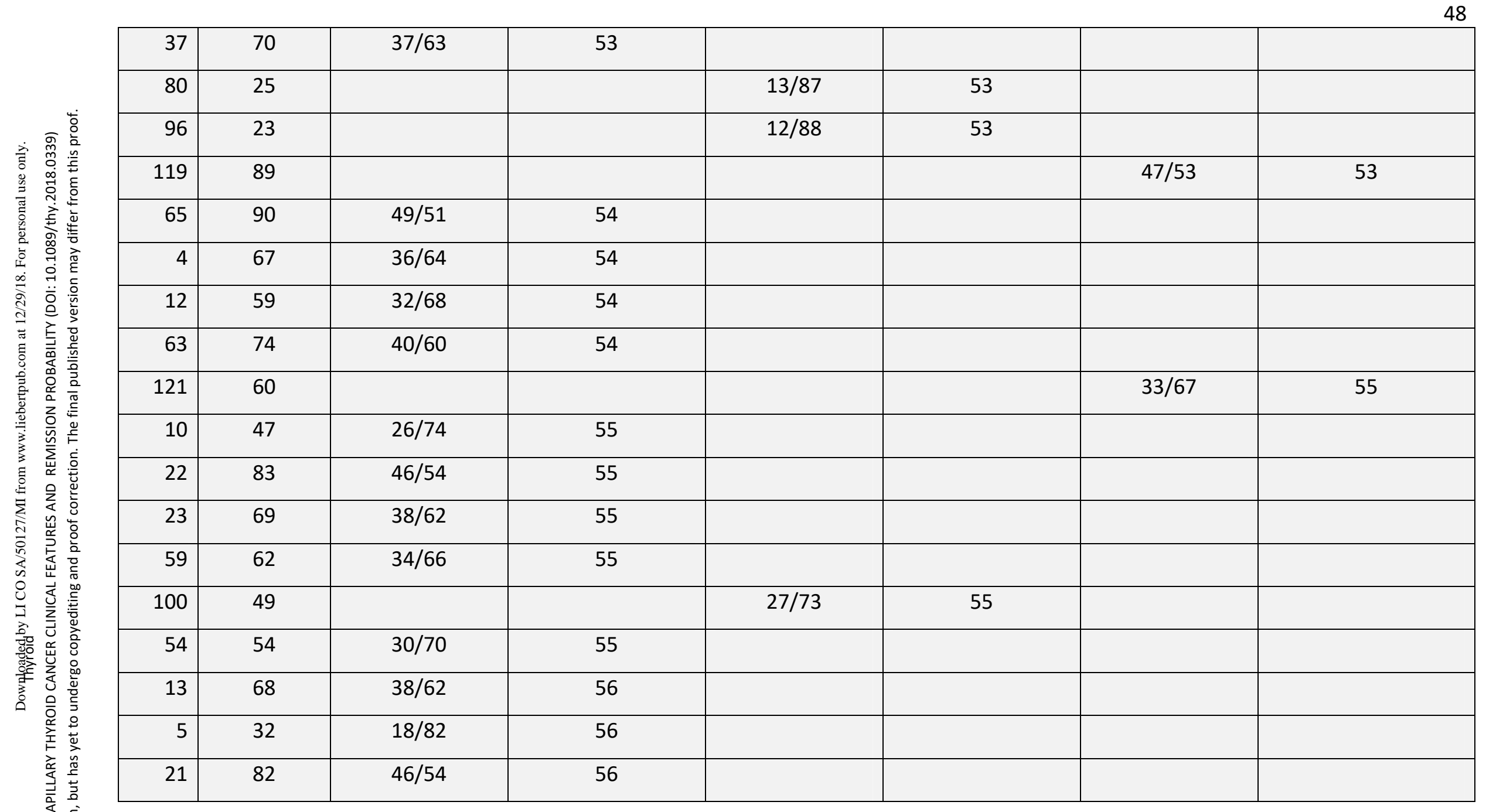




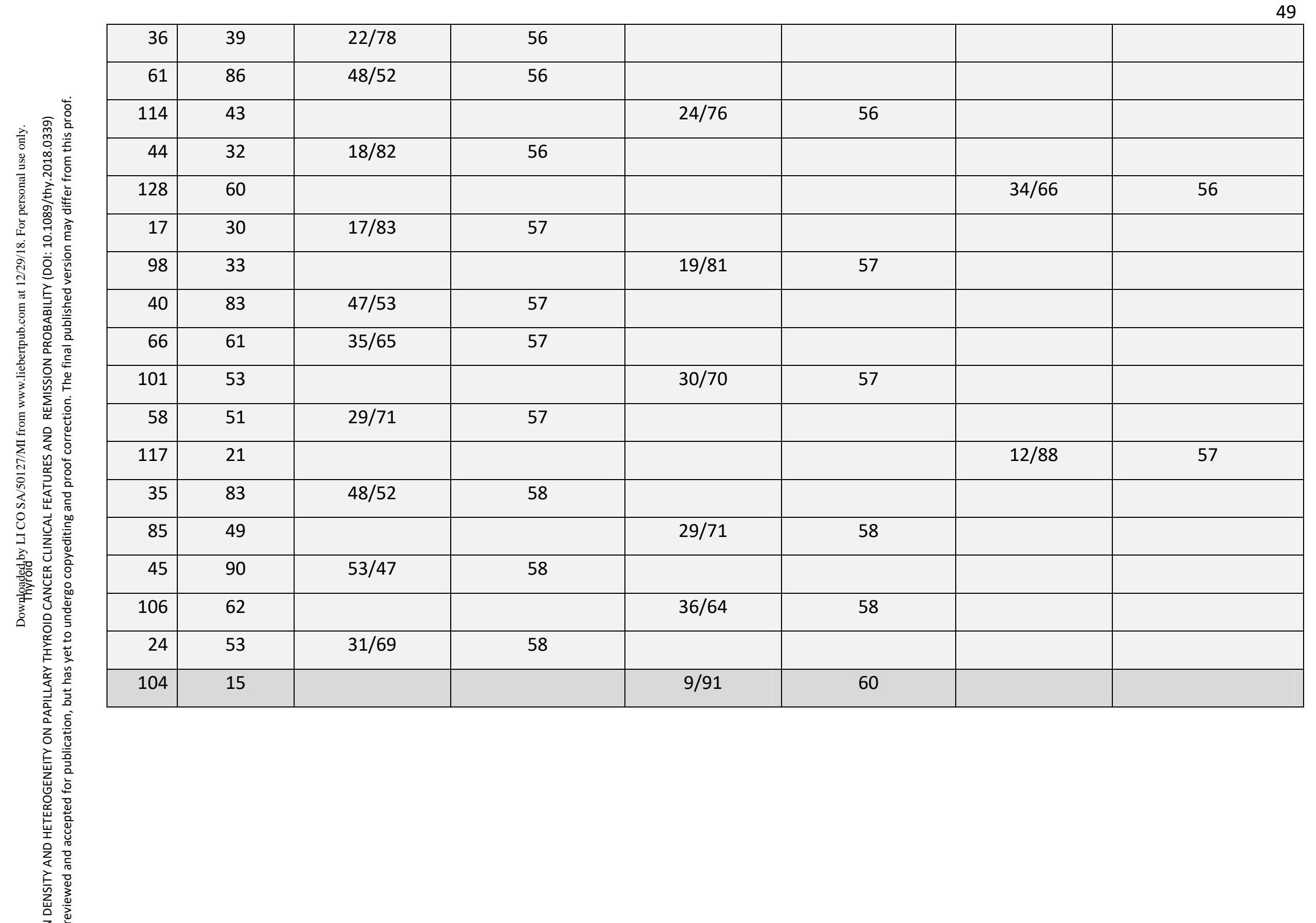


Page $\mathbf{5 0}$ of $\mathbf{5 2}$

50

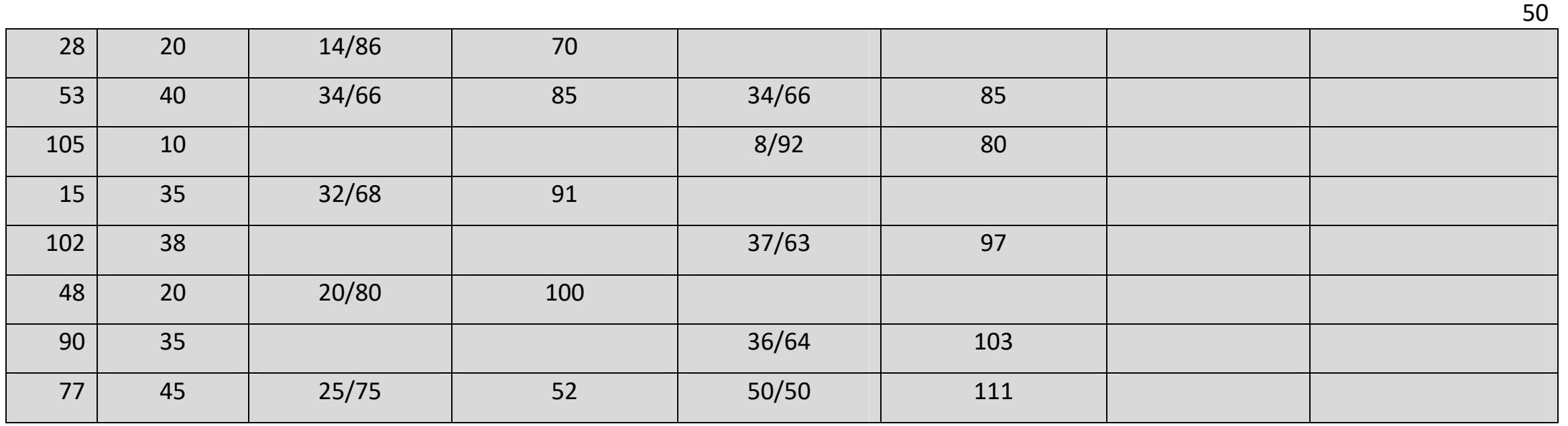



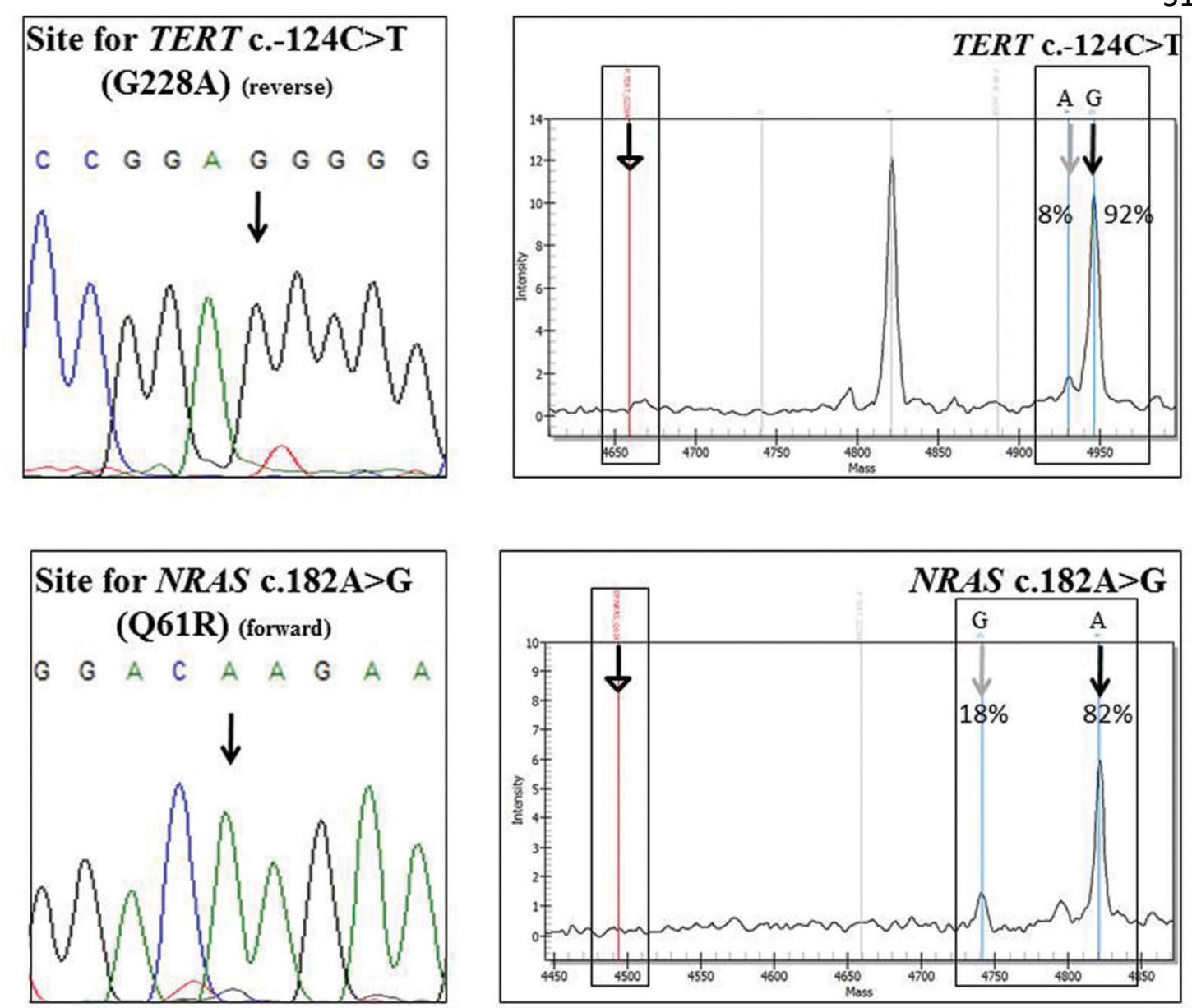

Supplemental Figure 1: Sanger sequences of TERT C.-124C $>T$ (G228A, reverse), and NRAS Q61R mutations and the corresponding MA spectra in two representative samples. In the electropherograms, black arrows indicate the putative mutated bases, which were erroneously identified as wild-type. In the MA spectrums, the boxed areas show the position of the investigated point mutation, the grey arrows indicate the mutated allele, the black arrows indicate the wild-type allele, and the empty arrow indicates the position of the extension primer. The frequencies of the mutated alleles were $8 \%$ and $18 \%$ for TERT and NRAS, respectively. 
BCPAP cells
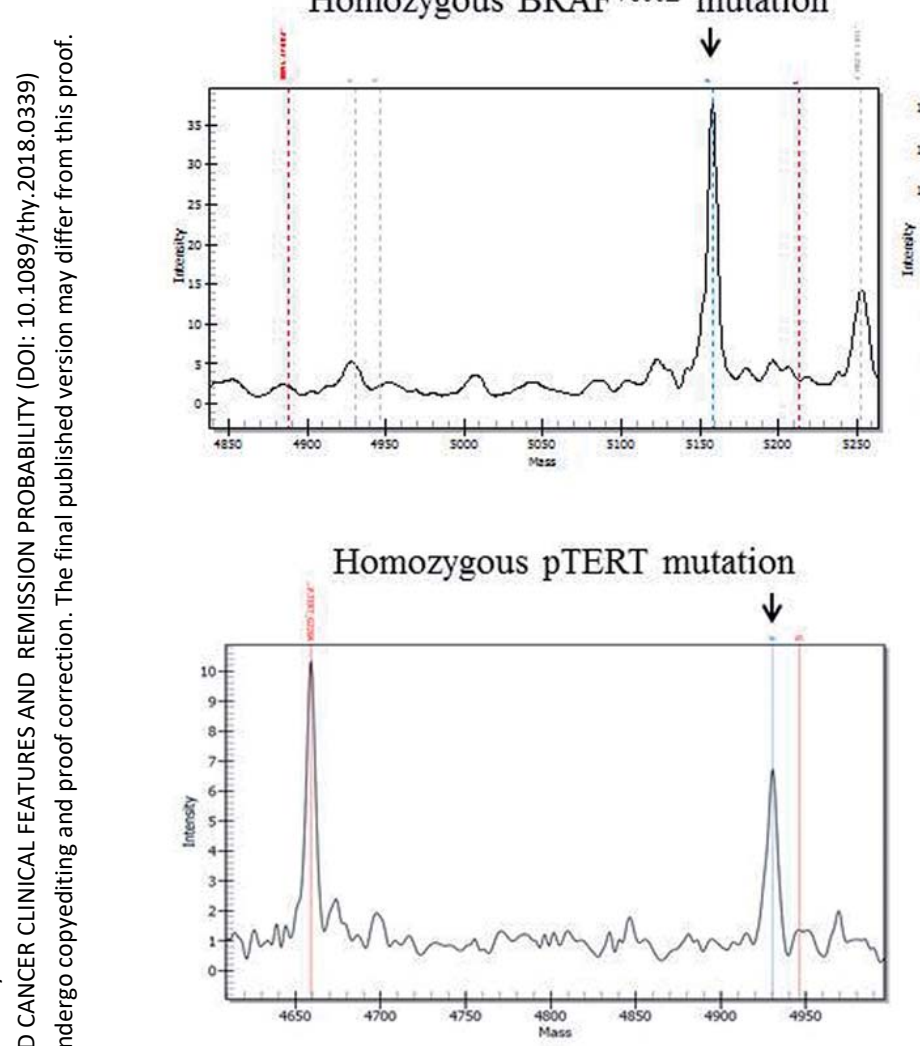

NIM cells

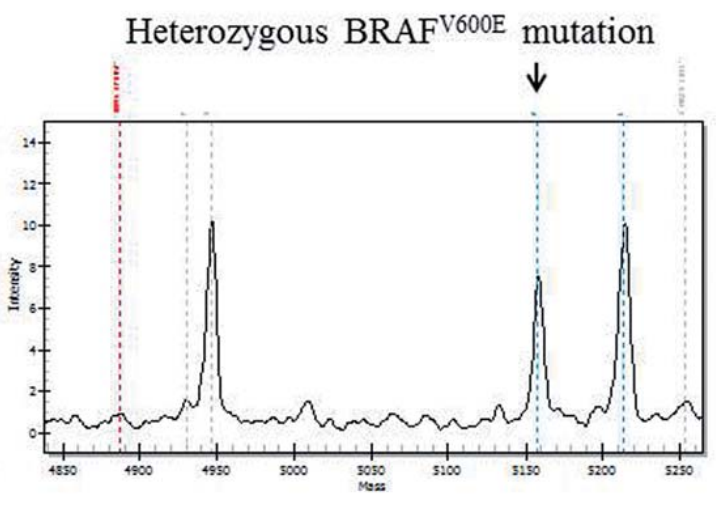

Supplemental Figure 2: MA spectra of BRAF and TERT analysis in BCPAP cells and of BRAF analysis in NIM cells. In the MA spectra, the black arrows indicate the mutated allele. The frequencies of the mutated alleles were 100\% in BCPAP and 50\% in NIM cells indicating the occurrence of the mutations in homozygosity and in heterozygosity, respectively. 